\title{
Data analysis of current and emerging skills development and training schemes in the rail transport sector
}

\author{
C. Cannon ${ }^{1} \bullet$ M. Marinov ${ }^{2} \bullet$ M. Robinson ${ }^{3}$
}

\author{
1James Calvert Spence College (JCSC), UK. \\ ${ }^{2}$ Engineering Systems and Management (ESM), Aston University, UK. \\ ${ }^{3}$ Future Mobility Group, School of Engineering, Newcastle University, UK.
}

${ }^{*}$ Corresponding author. E-mail: m.marinov@aston.ac.uk

Accepted $5^{\text {th }}$ March, 2019.

\begin{abstract}
Rail transport is one of the fastest growing industries in the world. High speed rail lines and networks have been built in many countries. New technologies and innovative concepts have been studied and implemented to modernise the entire rail sector. Currently there is an imminent need for building and maintaining a skilled rail workforce that will keep the industry growing sustainably. A skilled rail workforce is built and maintained through robust training schemes, programmes and curses. The aim of this study was to gain a better understanding of existing training schemes, programmes and courses for rail and to identify potential gaps in the availability of training schemes and programmes when looking at job categories in the entire rail sector across different sample countries, primarily from Europe. The methodology employed includes data collection for existing training schemes for job categories in various management levels using excel spreadsheets followed by statistical analyses. The findings suggest that internships and other schemes for skills development for job categories in the operational management level were the least provided training schemes overall. In contrast, skills development for job categories in the strategic and tactical management levels in the rail sector has more university-based and academic schemes available. Further work in this new research subject is needed to evaluate the quality of the courses provided and the courses provided in countries with lower economies.
\end{abstract}

Keywords: Rail transport, skills development, management, professional training, university programmes, courses, data analyses.

\section{INTRODUCTION}

The European Commission's $4^{\text {th }}$ Railway Package identified skills development in the rail sector as a priority area. It has been appreciated that "maintaining a skilled rail workforce" is an issue as "approximately $30 \%$ of all rail workers will retire in the next 10 years, probably leading to workforce shortages". Therefore, it is vital that there are enough available methods and resources to help build a new workforce to the required level for the future within the rail industry. As a result, the Commission is set on ensuring that the Member States can devise measures to create the necessary environment for skills development and give rail workers the right skills so that they can stay within employment in a vibrant railway sector (EC, 2013).

Potential railway workers have been gaining their skills in university programmes, intensive programmes, college-based programmes and training courses.

University programmes in rail have been discussed by 
Marinov and Fraszczyk (2013a, b). There are a few known MSc programmes to train potential rail workers, several available within Europe and other countries. A few known places are Newcastle University and La Sapienza in Rome. These offer courses based around rail Freight and Logistics, as well as Infrastructure and Railway Systems Engineering. These courses are said to equip graduates with the required skills to pursue their careers within the rail sector. They also offer some research modules which are almost like a research apprenticeship, helping learn in the rail environment. There are also some industry partners which are offered to those on these programmes, allowing them to gain some experience whilst being on the course.

Intensive programmes are another method of training potential rail workers, also discussed by Marinov and Fraszczyk. There are a few available across nine European universities, which are supported by the European Commission. These programmes involve academic learning with professionals over a short period of time. They can be attended by undergraduate students, for free in some cases, or they can be attended by home student however they are likely to have a fee. As an outcome, they are expected to produce a research report, a poster and a presentation. These are then judged, and certificates are received with details of the curriculum. This is beneficial as it is a short course meaning those short of time are still able to attend. Also, the quality of these courses is likely to be high as the students work with professors related to the rail industry.

Rail academies provide another method for potential workers to be trained for work in the rail industry. They provide a unique environment to help the student feel as though they are already working and help them easily change from the scholarly environment to the working environment. These academies offer the resources to train technicians and engineers for signalling, telecommunications, safety operations and infrastructure. They have advanced resources to allow for such advanced skills and qualifications to be gained. These can be attended by all interested however take place over an extended period of time like other various college courses. These are available in countries worldwide and within the EU (Newcastle College - Rail Academy, 2017, National Academy of Indian Railways, 2018, Land Transport Authority, 2017)

Some training courses are available to only those within employment. Companies find partners and then have their staff trained further through the available courses. Network Rail is an example of a company partner, which works with businesses that understand how to successfully run a railway and meet the needs of their customers. They work with industry partners to successfully train workers and ensure they have enough qualifications to help run the railways smoothly. These sorts of schemes are only available to those within employment which gives those wanting to train this way a disadvantage (Network Rail, 2017).

There are some graduate and apprenticeship schemes available within the rail industry. These work similarly to the rail academies as they involve a few years of working whilst earning a salary. They work within the real workplace meaning once they enter employment they will be used to the environment. These are available in several different sections, such as engineering and operations. These sorts of scheme allow for employment within host companies and help get those in training straight into a job (Rail Delivery Group, 2018).

The aim of this paper is to identify which job categories show gaps in training schemes and programmes within the rail transport sector, using data derived from a collective study. It involves a critical review and analysis, also shown using a visual presentation of the data collected from the review.

\section{METHODOLOGY}

The methodology employed in this study included data collection for available skills development schemes for job categories in the operational, tactical and strategic management levels for the entire rail sector, followed by statistical analyses. The data collected that allowed for comparison between the following 15 countries was accumulated using a template in Microsoft Excel; Australia, Belgium, Bulgaria, China, Germany, Greece, Ireland, Italy, Poland, Portugal, Romania, Slovakia, Spain, Sweden, United Kingdom.

The data is categorised according to a template of the career matrix shown in Figure 1. The career matrix is formed from a template laid out collectively, to list the job categories and positions in the rail transport sector against the three management levels for transport planning (Marinov et al., 2013; SKILLFUL, 2017; TunRail, 2011; Assad, 1980; Marinov, 2011), namely:

- Strategic management addresses decisions for changes in resource acquisition in the long term. Changes in the structure of the rail network, for instance, purchasing a new fleet and or building a new terminal. These decisions are associated with significant investments.

- Tactical planning focuses on resource allocation in the medium term. Timetables, schedules and shift allotment generally operate at the tactical level. It is important that activities at the tactical level are responsive to changes to customer requirements, available resources and assets.

- Operational management level deals with day-to-day activities of a railway company. For example, railorientated services, managing and running trains on a daily basis, loading and unloading operations, shunting and maintenance of trains in rail marshalling facilities and their depots.

Job categories include: 


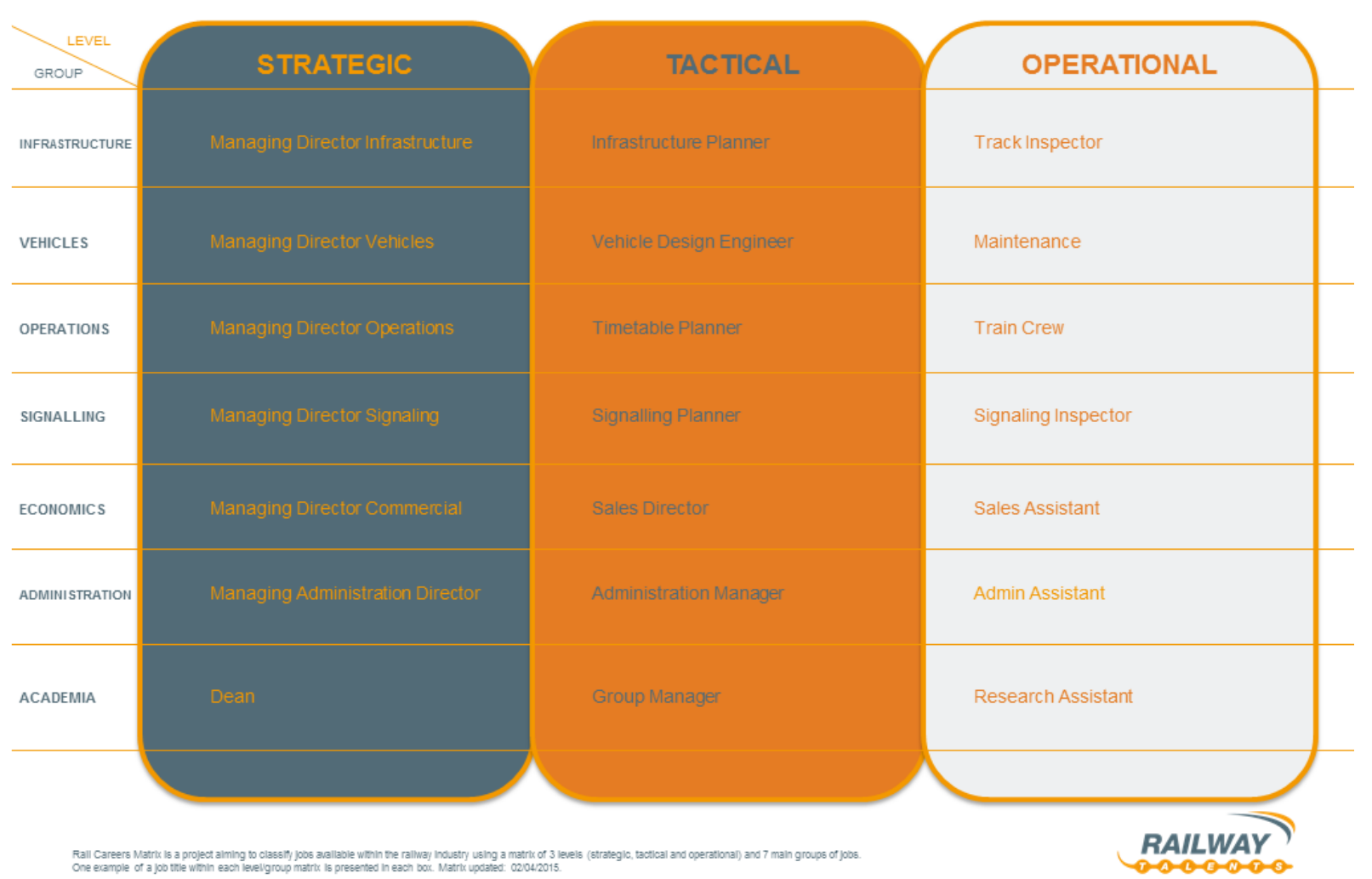

Figure 1. Rail careers matrix, developed by Marinov and Fraszczyk for TALENT, UIC.

- Infrastructure;

- Vehicles;

- Operations;

- Signalling;

- Economics;

- Administration;

- Academia.

To complete the template, each job categories was subdivided according to the following levels of training schemes and programmes:

- College;

- University;

- Professional Training;

- Apprenticeships;

- Vocational Education and Training (VET \& CVET);

- Others.

The data collected has been used to produce graphs that show trends and allow for the comparison of data for jobs and their categories. Within each of the management levels, a bar chart displays the percentage of training schemes and programmes available within each of the sample countries. The percentages expressed reflect the actual number of schemes provided out of the possible
42 per sample country per management level. There are also pie charts that show the distribution of the courses amongst the fields of education at each management level and across each of the sample countries. The data is not taken from a set amount of time and does not give specific numbers of courses, meaning it can be considered reliable.

\section{ANALYSIS OF DATA}

Distribution of training schemes and programmes in rail transport in sample countries at management levels

The majority of the data presented in this section is processed with each graph made using Microsoft Excel. Figure 2 displays the total number of training schemes and programmes spread across all the sample countries combined.

Figure 2 shows the number of all training schemes and programmes of all sample countries combined. The figure shows that $21.8 \%$ of all variables received a 'Yes' answer, meaning that on average $21.8 \%$ of all training schemes and programmes are provided in each of the sample countries. Only $21.8 \%$ of a possible 1890 courses 


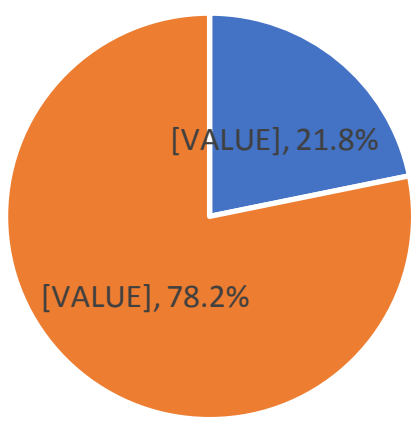

- Percentage of 'Yes' Answers on all Levels - Percentage of 'No' Answers on all Levels

Figure 2. Number of all training schemes and programmes.

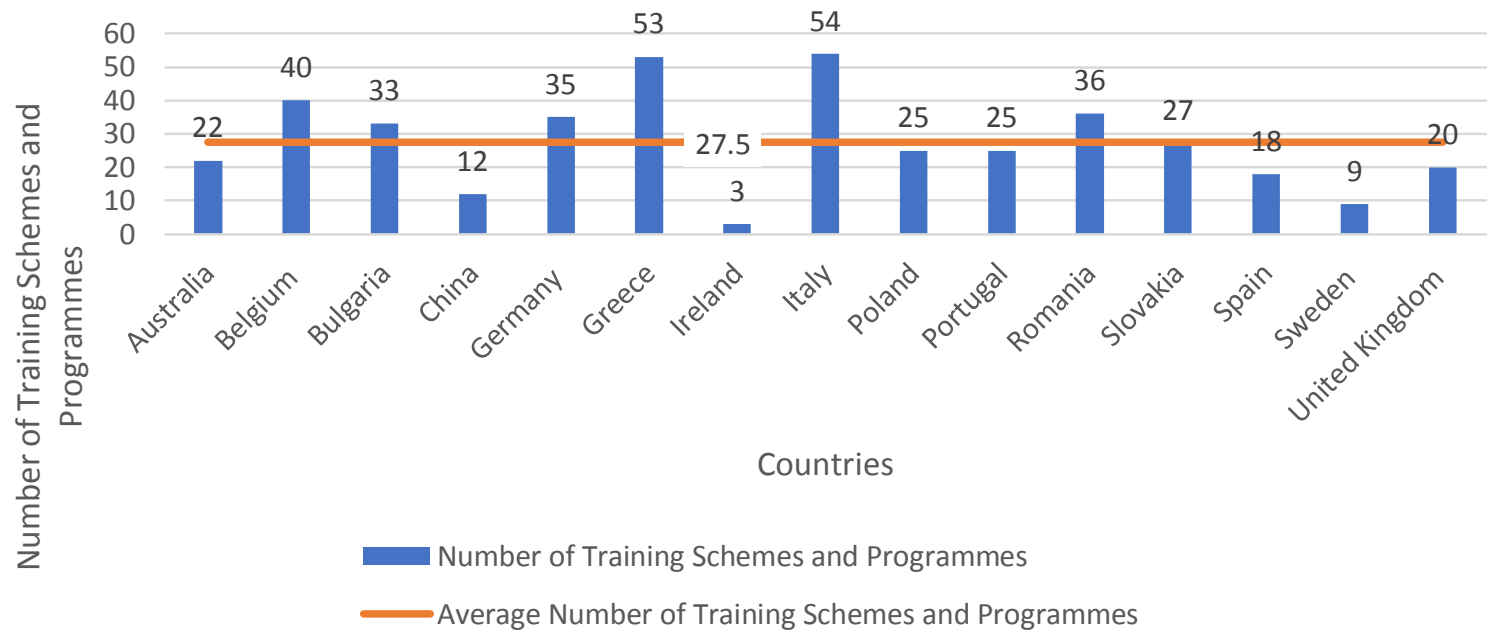

Figure 3. Number of training schemes and programmes available in all sample countries.

are offered across all of the sample countries. This suggests that there is a severe shortage in rail education and training schemes.

Figure 3 displays the total number of training schemes spread across all management levels and job categories. There is a large amount of deviation about the average of 27.5 , which suggests there is a lot of variation in the availability of training courses among the sample countries. It is observed that Italy has the highest number of training schemes, 54 programmes available across all management levels and job groups. In comparison, it is observed that Ireland offers the fewest number of training schemes, 3 programmes available across all management levels and job groups. However, these numbers do not necessarily mean that there are training schemes and programmes available for every management level across each job group.

Figure 4 shows the proportion of training schemes and programmes that are available, out of all the potential 126 courses that could be provided at all management levels and job categories. The percentage gives the 'Yes' answers in each country out of their possible 126 courses. Again, this demonstrates that Italy offers the most training schemes and programmes and that Ireland offers the fewest.

Figure 5 shows the actual proportion of skills development and training schemes that are available, out of all potential courses that could be provided at all management levels and job categories in all sample countries. It is observed that the 'operational' management level offers the highest number of courses, with $25.1 \%$ of the possible 630 schemes and programmes being offered. The 'strategic' management level offers the fewest courses, with $19.7 \%$ of the possible 630 schemes and programmes being offered. Both the 'strategic' and 'tactical' levels are below the average of $21.8 \%$ however, there is little variation about this average.

Figure 6 displays the proportion of training schemes and programmes available at the strategic management level. It can be seen that there is a large amount of variation about the $20 \%$ average value. The country with the highest proportion of training schemes and programmes at this management level is Italy at $50 \%$ and 


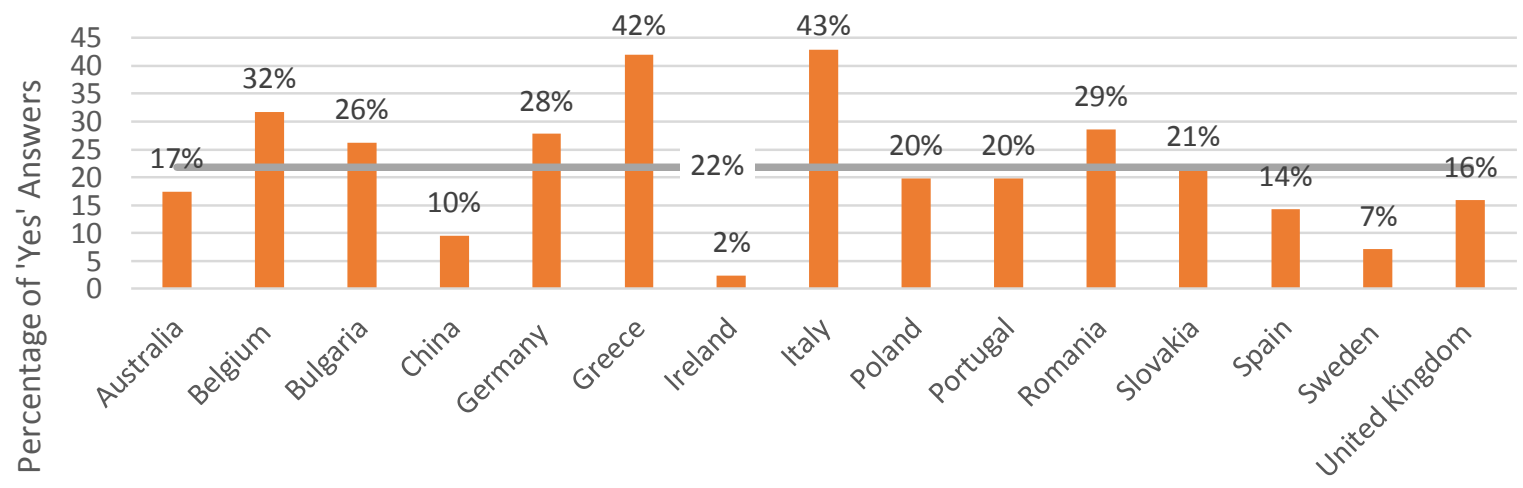

Countries

Percentage of 'Yes' Answers

Average Percentage of 'Yes' Answers

Figure 4. Percentage of training schemes and programmes available in all sample countries.

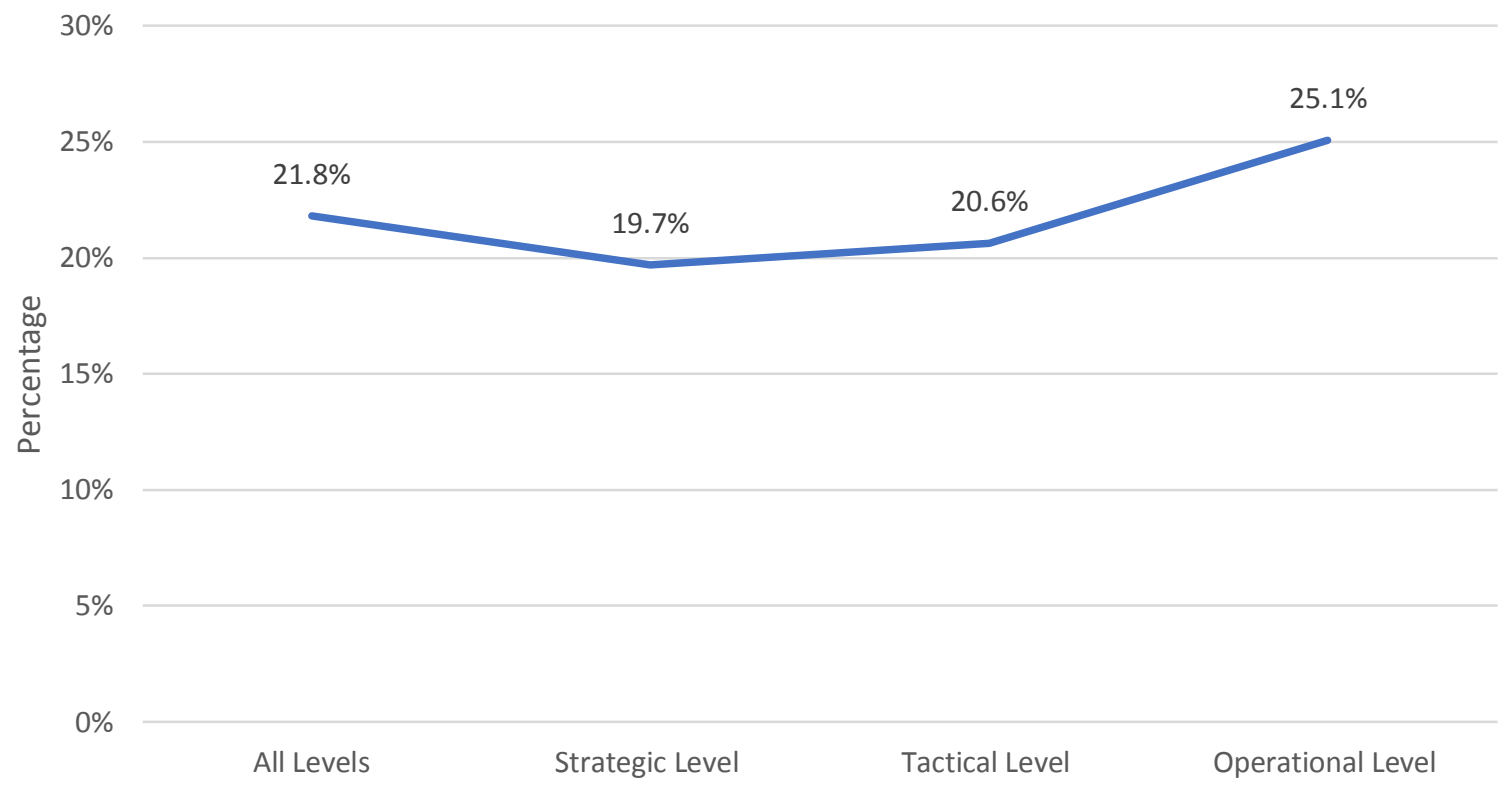

Figure 5. Average number of 'yes' answers at each of the 3 management levels.

the countries with the lowest proportions are both Ireland and Sweden at $2 \%$.

Figure 7 displays the proportion of training schemes and programmes available at the tactical management level. It can be seen that there is a large amount of variation about the $21 \%$ average value. The country with the highest proportion of training schemes and programmes at this management level, similarly to the strategic level, is Italy at $50 \%$ and, again, the countries with the lowest proportions are both Ireland and Sweden at $2 \%$.

Figure 8 displays the proportion of training schemes and programmes available at the operational management level. It can be seen that, compared with the other management levels, there is less variation around the average of $25 \%$. The country with the highest proportion of training schemes and programmes at this management level is Greece at $55 \%$. The country with the lowest proportion is Ireland at $2 \%$.

\section{Distribution of training schemes and programmes amongst fields of education}

Figure 9 shows that most training schemes are provided at the University level, with $34 \%$ of 412 schemes and programmes being offered at this level, this is followed by those at the Professional Training level at $24 \%$. 


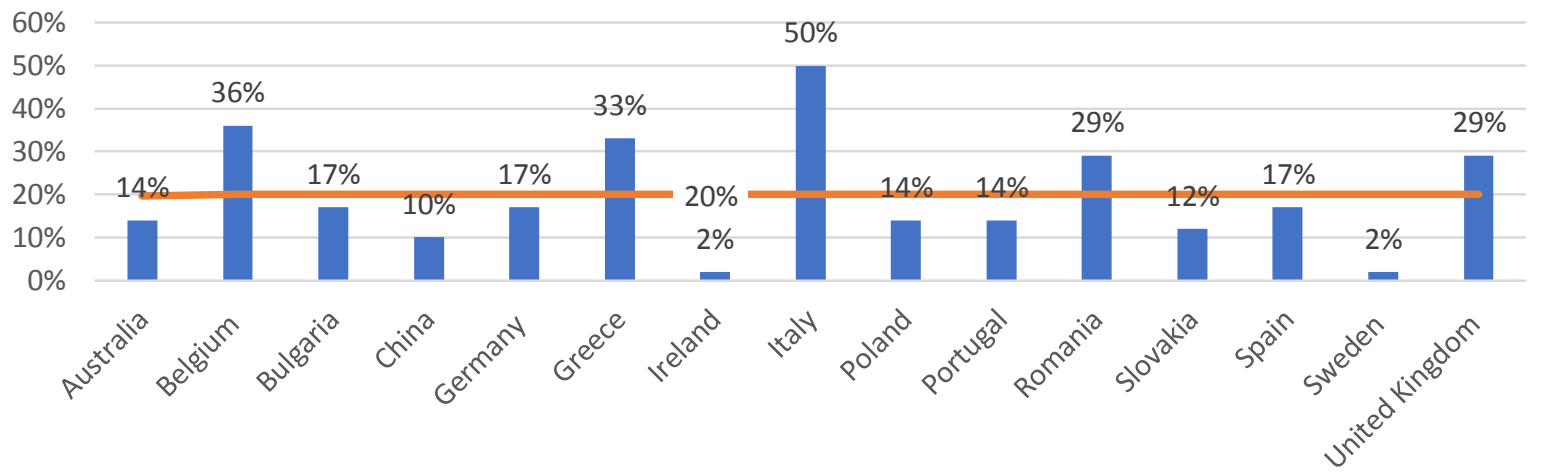

Percentage of 'Yes' Answers $\quad$ Average Percentage of 'Yes' Answers

Figure 6. Percentage of training schemes and programmes available as a proportion of all possible programmes at the strategic management level for all sample countries.

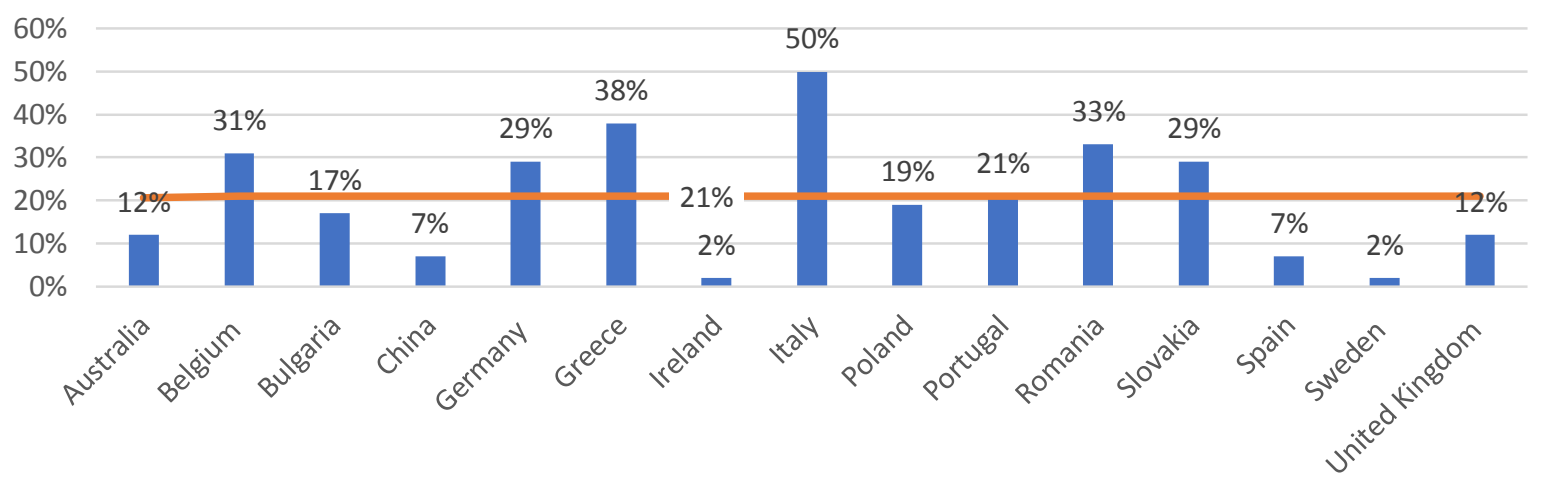

Percentage of 'Yes' Answers —Average Percentage of 'Yes' Answers

Figure 7. Percentage of training schemes and programmes available as a proportion of all possible programmes at the tactical management level for all sample countries.

Apprenticeships and other training schemes are the least utilised, both contributing $8 \%$, followed by Colleges at $9 \%$. Vocational Education and Training (VET \& CVET) is in the middle of the training distribution, contributing $17 \%$ of training schemes and programmes.

Figure 10 shows the distribution of training schemes and programmes within each management level. Most courses are provided at a university, followed by professional training, at the strategic level. At the tactical management level, most of the training courses are also provided at a university, followed by both professional training and vocational education and training (VET \& CVET). Unlike the other management levels, most of the operational management courses are taught through professional training schemes, followed by those taught through vocational education and training (VET \& CVET).

By comparing the 2 figures, it can be seen that some of the fields of education in Figure 10 have different distribution to those seen in Figure 9. For example, the distribution of courses at a university at the strategic and tactical levels are around $10 \%$ higher than expected, whereas the operational level is almost $20 \%$ lower than expected. Also, apprenticeship schemes at the strategic and tactical management levels are lower than expected whereas the operational level is higher than expected.

\section{Distribution of training schemes and programmes within management levels}

Figure 11 shows the distribution of training schemes and programmes amongst the management levels. It can be seen that the total number of courses available across all sample countries is evenly spread throughout each management level; however, the operational level clearly offers the most by a small percentage. The strategic and tactical management levels each provide about 30\% each.

Figure 12 shows that at the strategic management level that most of the courses are provided at the University 


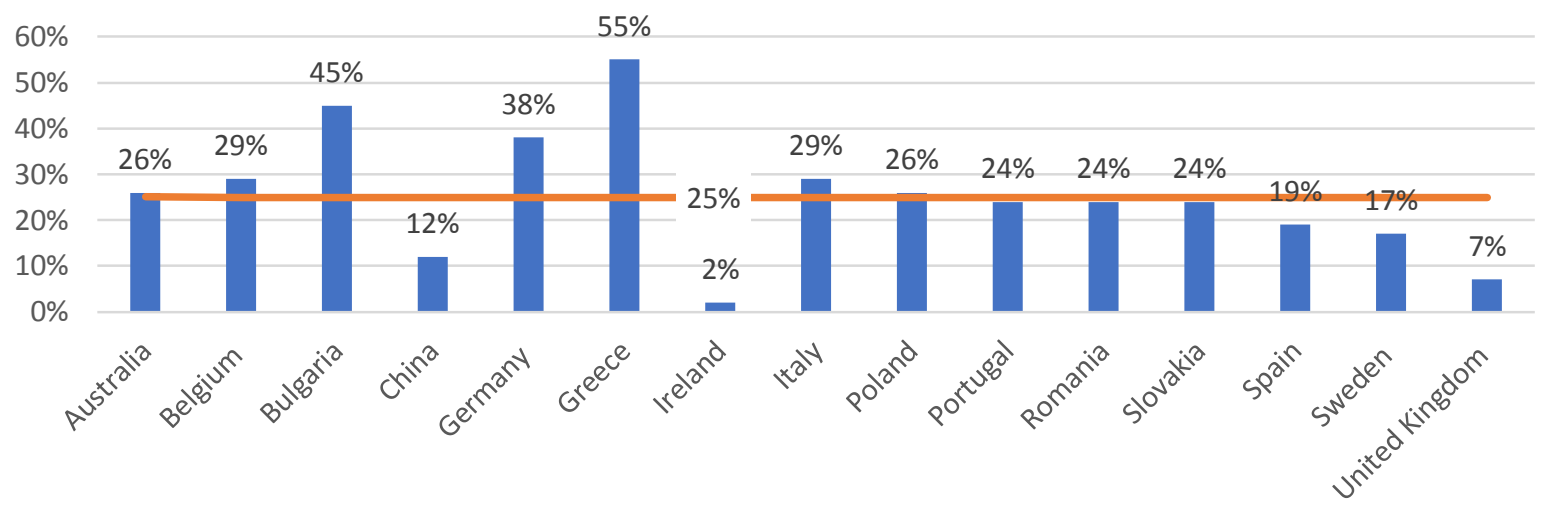

Percentage of 'Yes' Answers _ _ Average Percentage of 'Yes' Answers

Figure 8. Percentage of training schemes and programmes available as a proportion of all possible programmes at the operational management level for all sample countries.

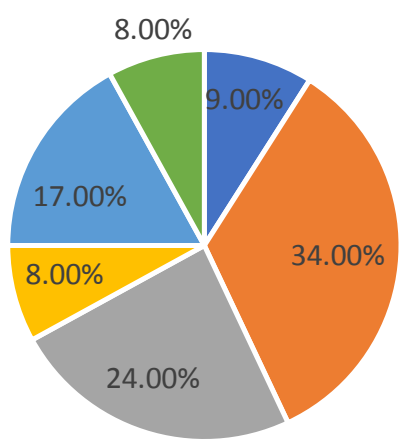

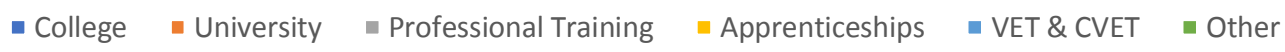

Figure 9. Distribution of training schemes and programmes provided by each field of education.

level, with it occupying $45 \%$ or almost half of all strategic level courses. It can be seen that professional training schemes provide over one-quarter of the training schemes at the strategic management level. When combined with the university courses, these provide almost three-quarters of all the programmes at this level. In contrast, apprenticeships account for a mere $3 \%$ of all training schemes provided at the strategic management level.

Figure 13 shows that there is a similar amount of higher education courses provided at the tactical management level. Like the strategic level, most courses are provided at the university level, with this type of education providing $44 \%$ of all training schemes available at the tactical level. The next most common are professional training schemes, like at the strategic level, and vocational education and training (VET \& CVET); both at $20 \%$. In comparison to the strategic level, only $11 \%$ of training schemes are provided by vocational education and training (VET \& CVET), almost half of those provided at the tactical level.
Figure 14 shows that there are far fewer courses offered at an institution of higher education at the operational management level. In contrast to the strategic and tactical management levels, the most courses are offered by professional training schemes for the operational management level, with $27 \%$ of the courses being offered. Like as seen at the tactical level, the next most common type of scheme is vocational education and training (VET \& CVET) at $20 \%$.

Figures 15 and 16 show the distribution of management levels within the fields of education. Within colleges, it can be seen that there are far more courses provided at the operational management level than those available at the strategic and tactical management levels. $55 \%$ of the courses are provided on the operational level which shows over half of the courses are provided here.

At university, the distribution of courses provided shows that most of the courses are shared equally between the strategic and tactical management levels, both providing around $40 \%$ each. The operational level providing just under half of the courses provided by the strategic and 


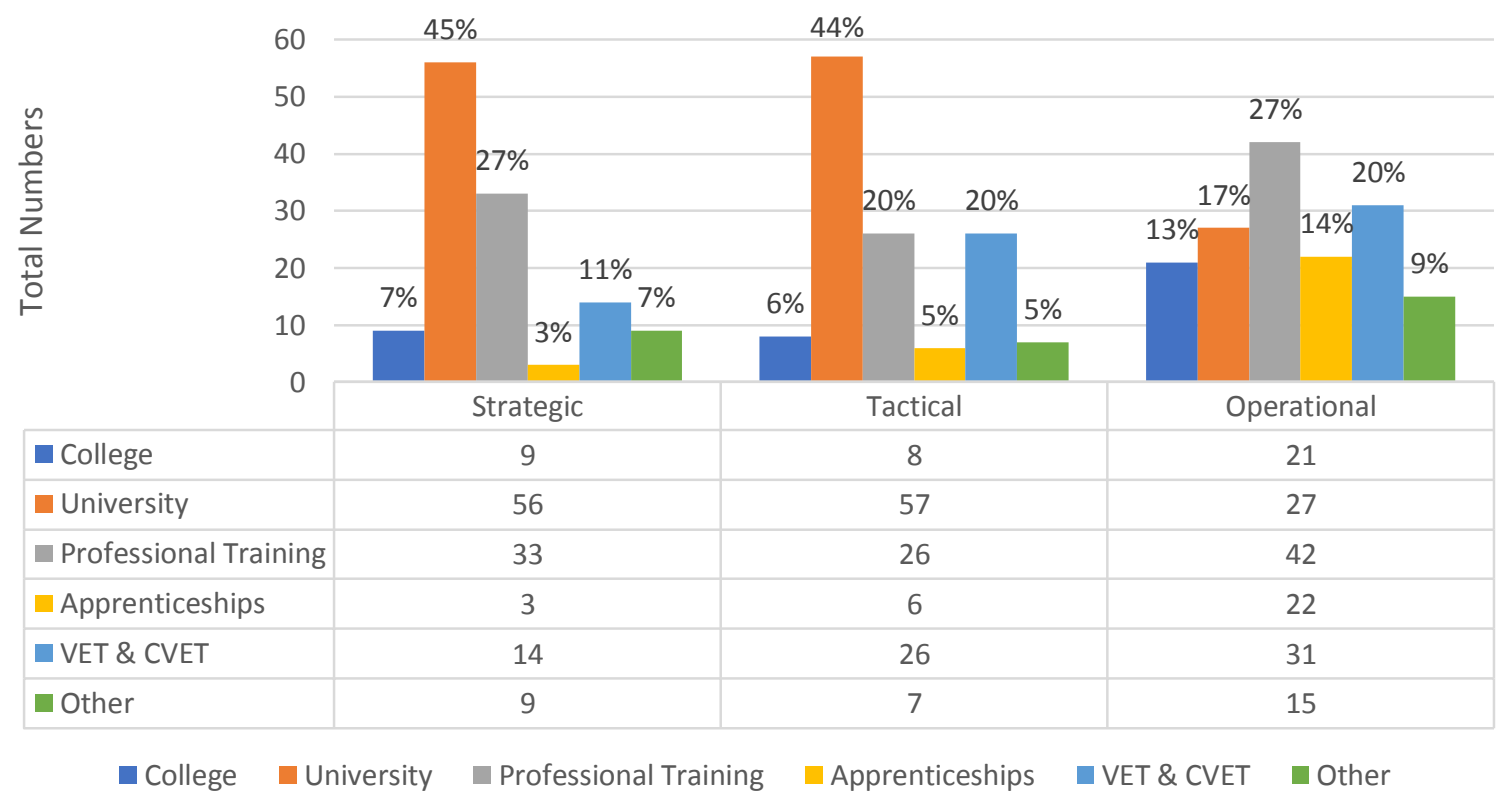

Figure 10. Distribution of categories of training schemes and programmes amongst fields of education within each management level.

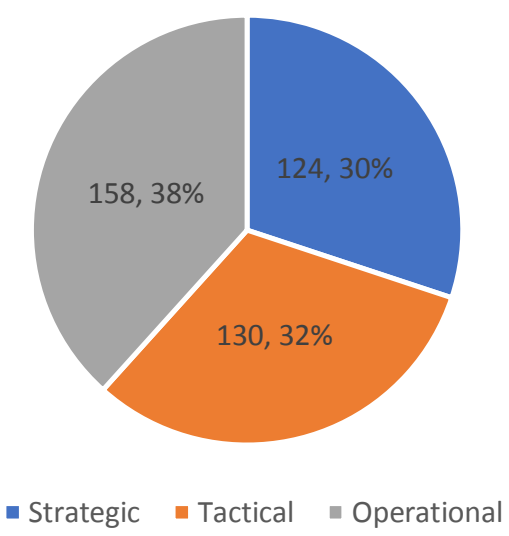

Figure 11. Distribution of training schemes and programmes amongst management levels.

tactical levels at $19 \%$.

Professional training schemes are the least provided at the tactical management level at only $26 \%$.

With regards to apprenticeships, almost three-quarters are provided at the operational management level, followed by the tactical level and then the strategic level. The percentage difference is strongest amongst this field of education.

Training schemes and programmes provided by Vocational Education and Training (VET \& CVET) are mainly at the operational management level with $44 \%$, followed by the tactical and the strategic level.

Training schemes and programmes in the "other" category are provided mainly by the operational management level, followed by the strategic level then the tactical level. The operational level provides almost half of the courses.

These figures both show that within each field of education, the management levels are not evenly distributed. The most evenly distributed would be onethird in each, however, the closest is found in "professional training".

Other categories are much more uneven, for example at university $80 \%$ of the training schemes are provided at the strategic and tactical levels. For apprenticeships, 71\% of the training schemes and programmes are provided at the operational management level.

Figure 17 looks at the total numbers of training schemes and programmes provided within each field of education. The field that has the most schemes is universities, with a total of 140 across all three of the management levels. The fields that offer the fewest number of training schemes and programmes are both apprenticeships and other types of training, each having 31 courses across the three management levels.

\section{Distribution of training schemes and programmes amongst job groups}

Figure 18 looks at the total number of training schemes and programmes distributed amongst the different job groups. Most of these schemes are offered within the infrastructure job group, with 87 of them being provided across each of the management levels. The job group that offers the next highest number of schemes is signalling, with 67 being provided across the management levels. The fewest training schemes and programmes are provided within the academia job group, 


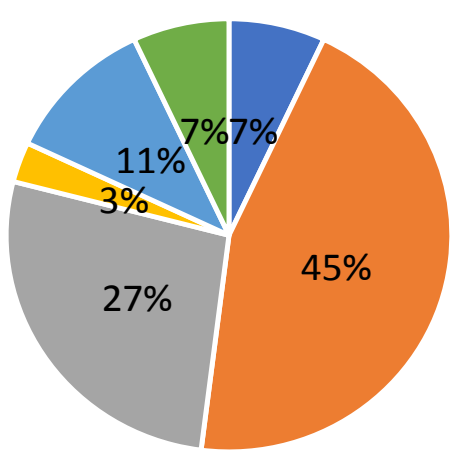
- College
- University
- Professional Training
Apprenticeships
- VET \& CVET
Other

Figure 12. Distribution of training schemes and programmes within the strategic management level.

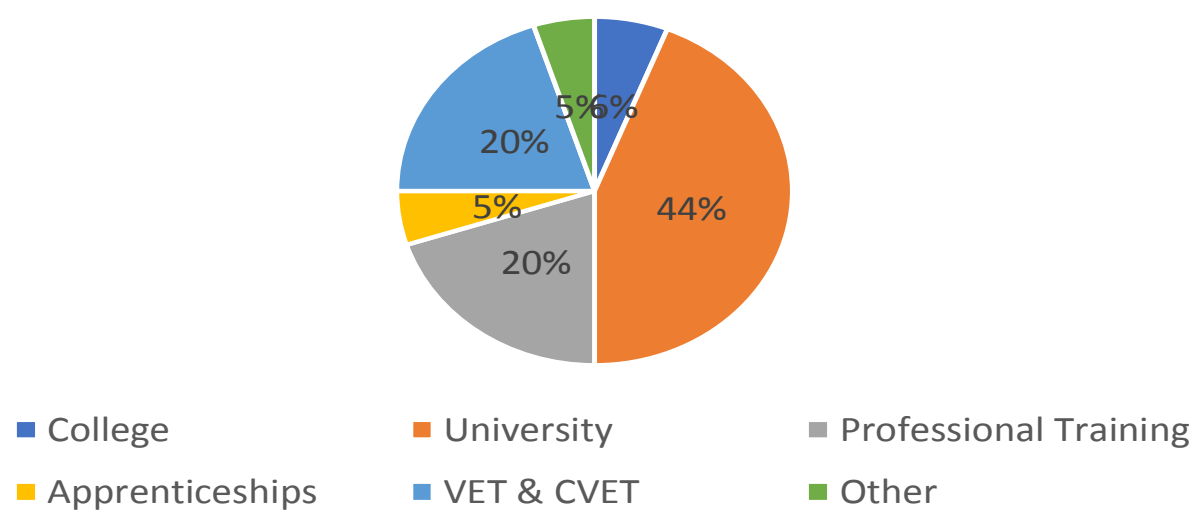

Figure 13. Distribution of training schemes and programmes within the tactical management level.

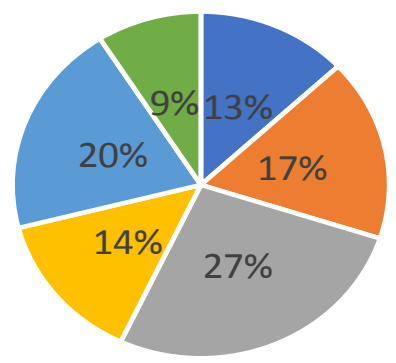
- College
- University
- Professional Training
- Apprenticeships
- VET \& CVET
- Other

Figure 14. Distribution of training schemes and programmes within the operational management level.

with only 28 being provided across the management levels.

Figure 19 shows the distribution of training schemes and programmes at the three different management levels within the job groups. It can be seen that the majority of the training schemes and programmes offered 


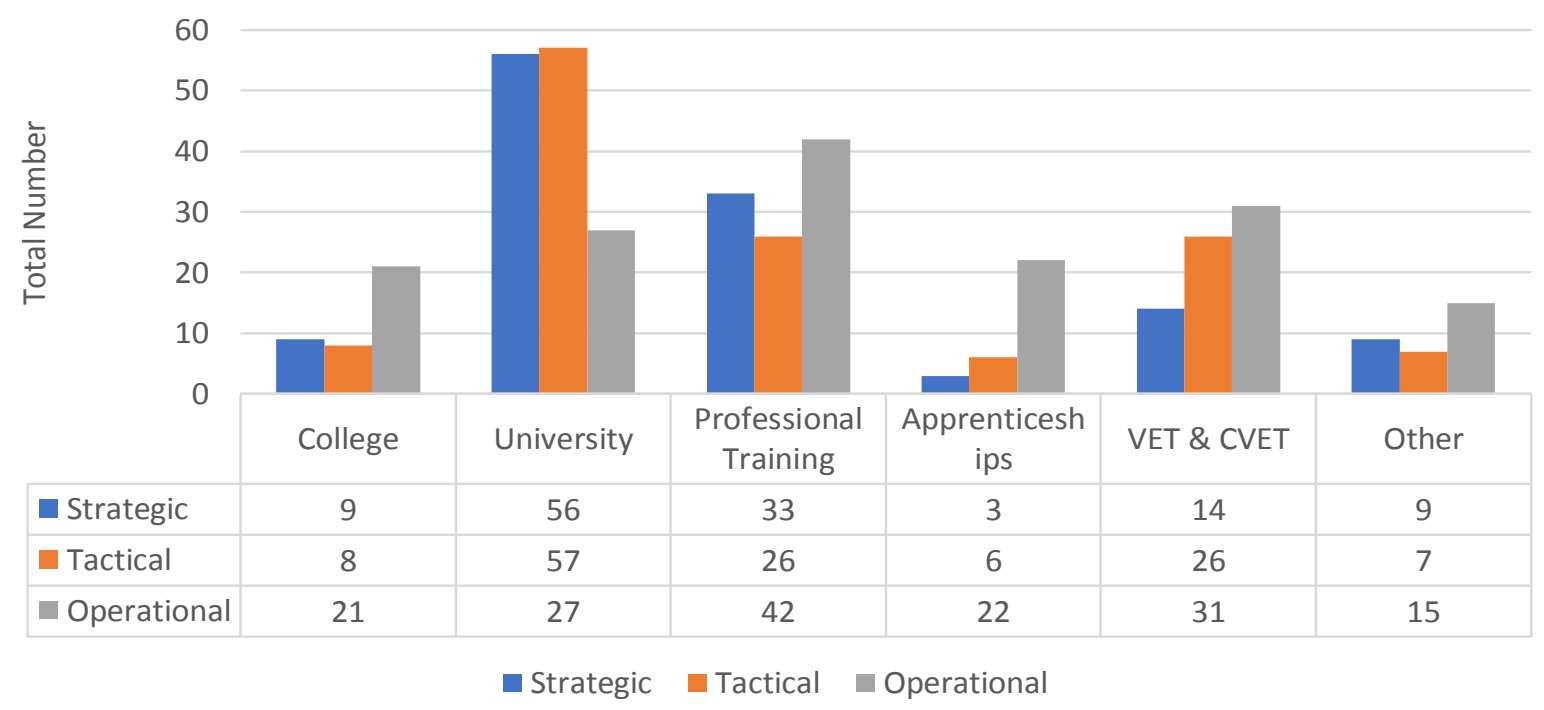

Figure 15. Distribution of management levels within the categories of training schemes and programmes.

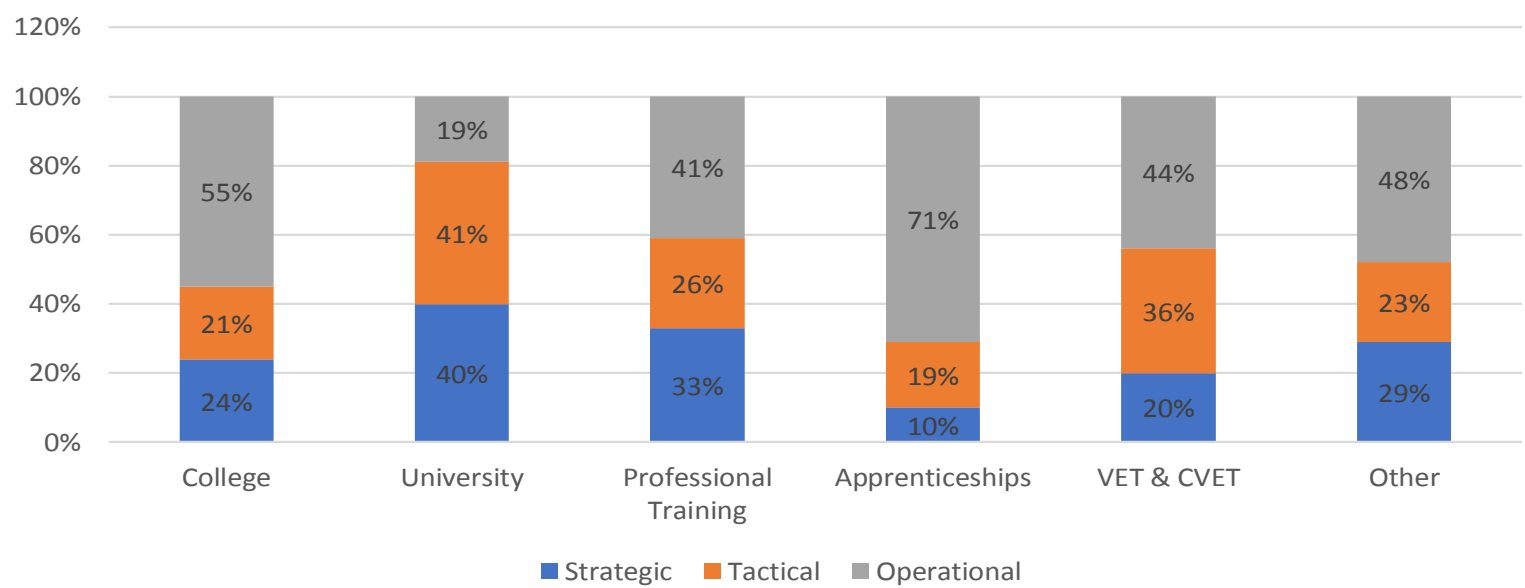

Figure 16. Distribution of management levels within the categories of training schemes and programmes.

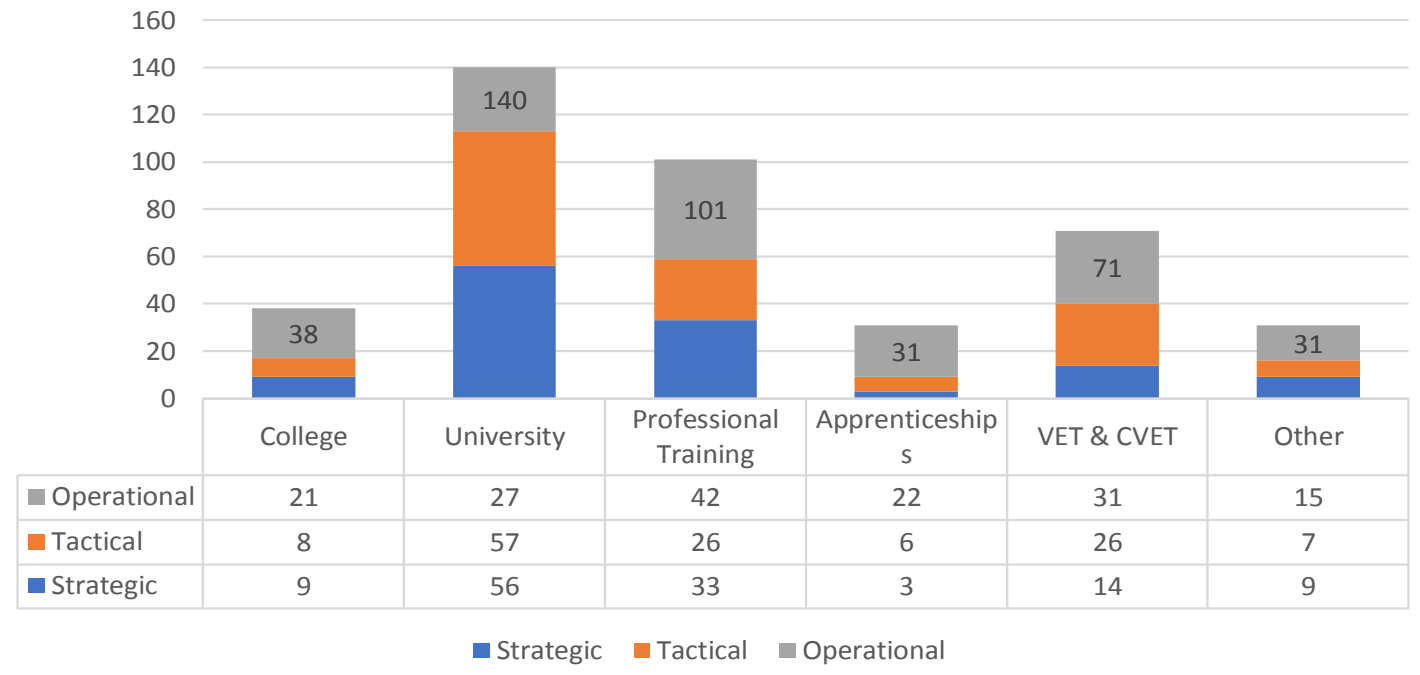

Figure 17. Distribution of management levels within categories of training schemes and programmes. 


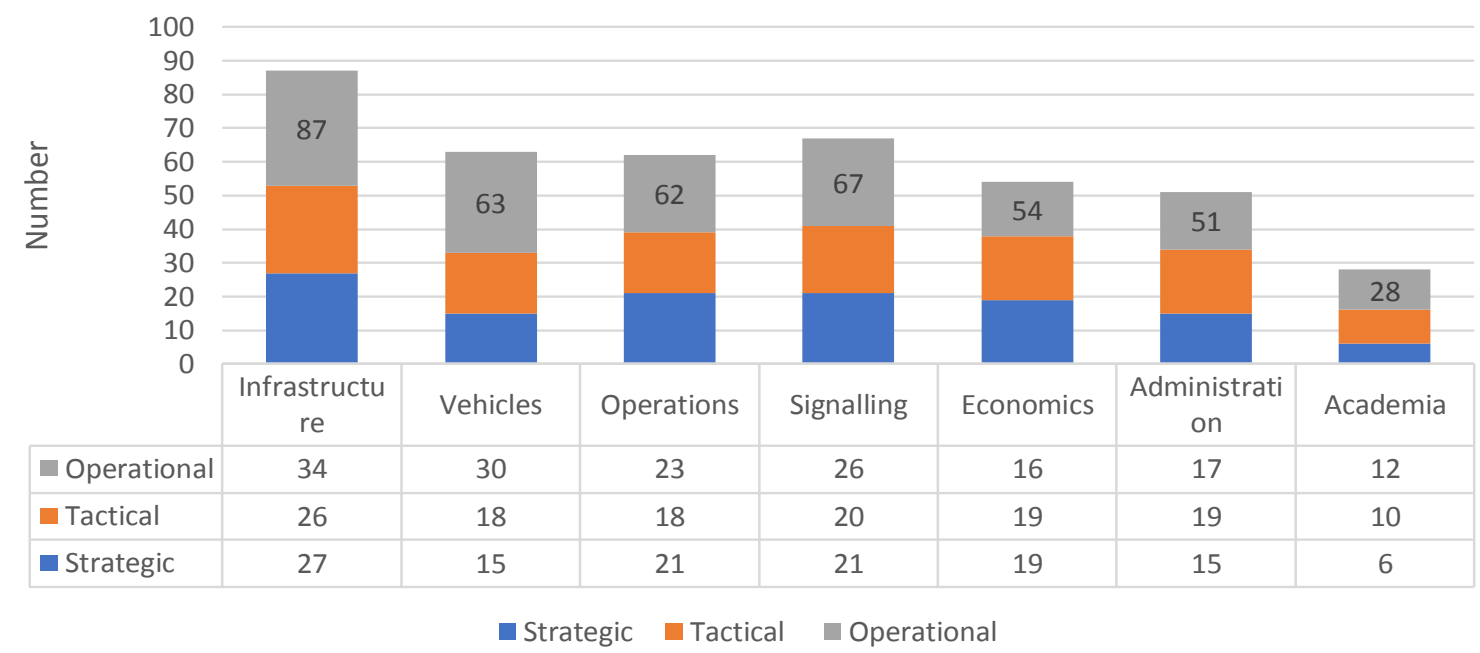

Figure 18. Distribution of number of training schemes and programmes amongst job groups.

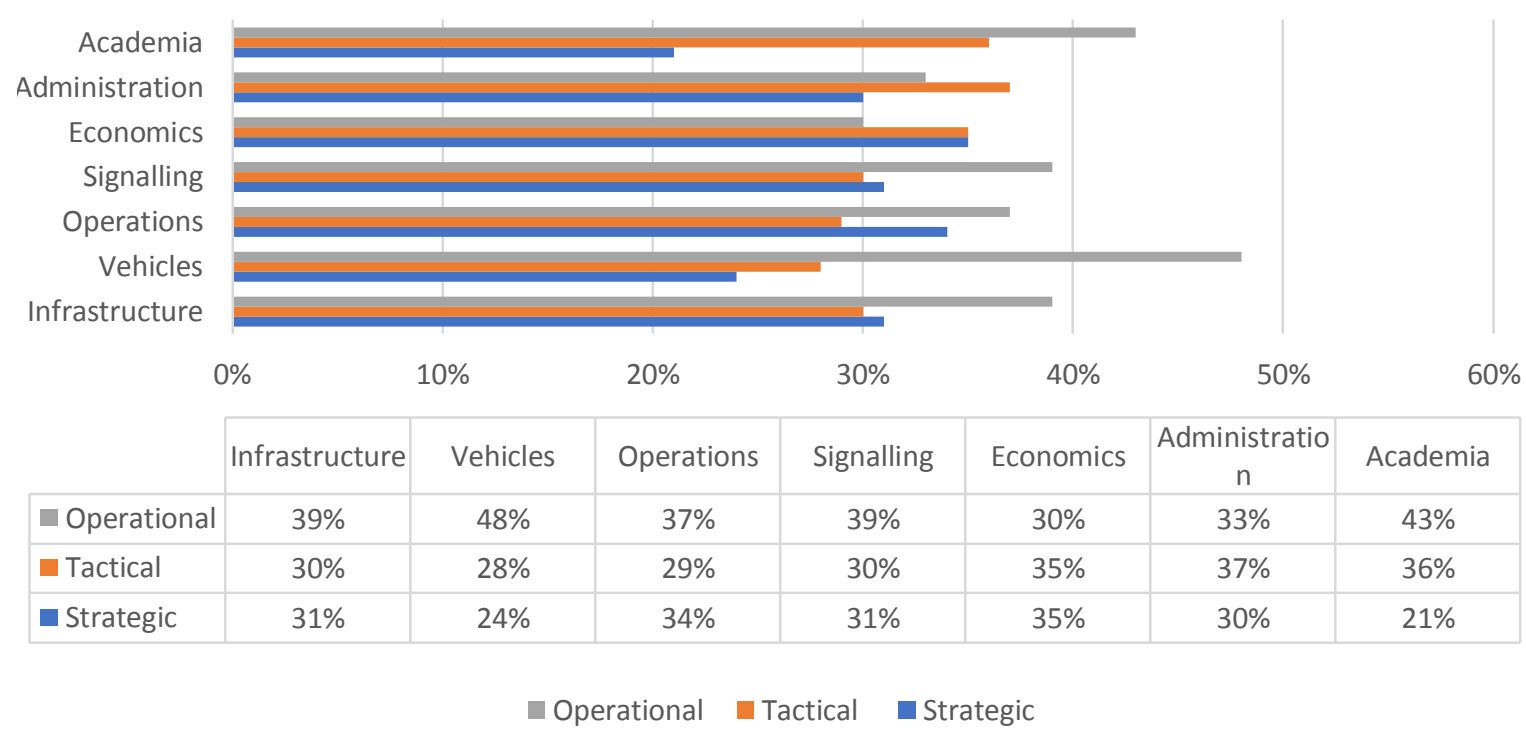

Figure 19. Distribution of training schemes and programmes on the three management levels within the job groups.

in all job groups are at the operational level. In the administration job group, the majority of its training schemes and programmes are offered at the tactical management level compared with the other levels. In the economics job group, the strategic and tactical management level share an equal distribution of the number of training schemes, with $35 \%$ of each being offered compared with the $30 \%$ offered by the operational management level.

The majority of training schemes and programmes are offered within the infrastructure job group, with $21 \%$ (Figure 20). Signalling offers the second highest number of courses, followed by operations and vehicles, then economics and administration. This figure shows that 5 of the 7 job groups have a fairly even distribution. However, it is clear that one group is at the top, which is the infrastructure group with a $5 \%$ margin to the next most offered group. The group at the bottom is academia, again with a $5 \%$ margin to the next offered group.

From this, it can be concluded that a lot more training schemes and programmes in the rail sector are offered for infrastructure-related jobs and that very few are offered for academia-related jobs in the rail industry.

\section{Distribution of training schemes and programmes within infrastructure}

This section examines the infrastructure job group in further detail, with the focus being on the areas where 

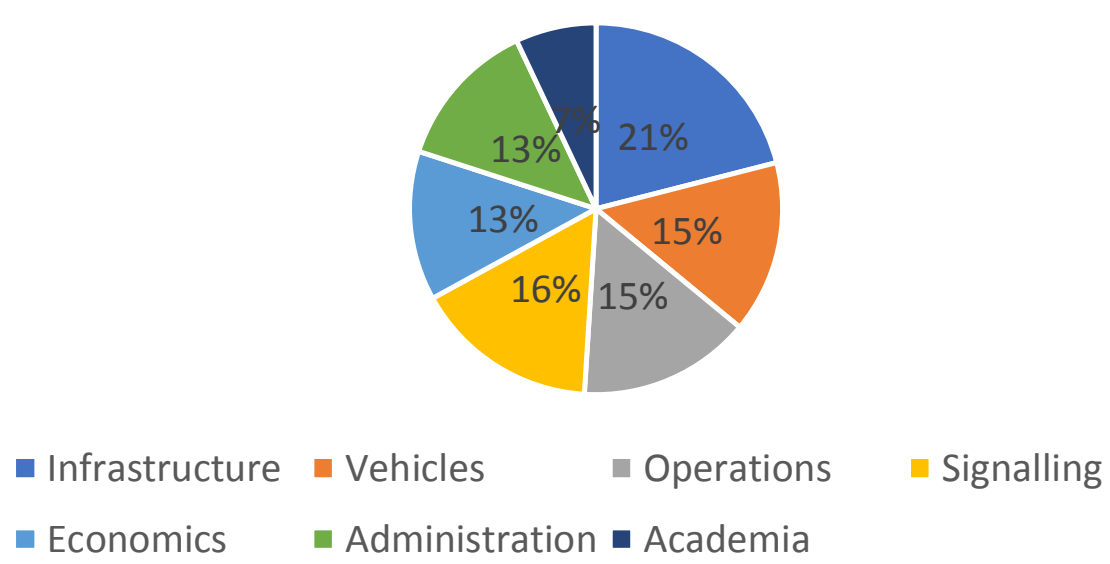

Figure 20. Distribution of training schemes and programmes amongst job groups.

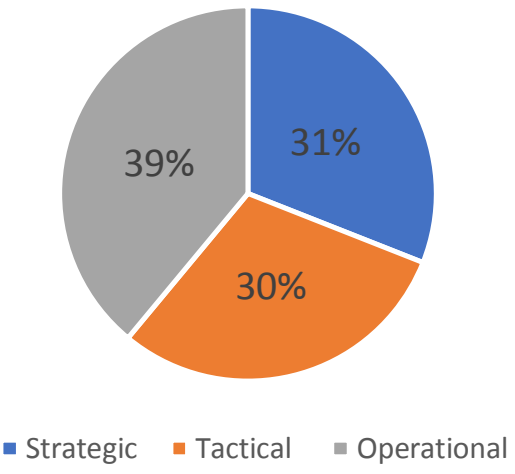

Figure 21. Average distribution of training schemes and programmes spread across the management levels in the "Infrastructure" job group.

there are gaps in the provided training schemes and programmes.

Figure 21 shows the distribution of training schemes and programmes in the infrastructure job group. Nearly $40 \%$ of the 87 courses provided in infrastructure are provided at the operational management level, with the strategic and tactical management levels having an even proportion of the remaining courses with around 30\% each.

Figure 22 shows the distribution of training schemes and programmes amongst all fields of education and levels of management for infrastructure. The graph shows that in the infrastructure job group, it follows the trend that apprenticeships and other schemes provide the least courses for the management levels.

Although the operational management level contrasts, it can be taken from the graph that most courses within infrastructure are provided at universities. Operational management, on the other hand, offers the majority of its courses through professional training schemes; all of these conclusions agreeing with the trend set out in Figure 10. Vocational education and training (VET \&
CVET) are the least provided scheme at the operational management level, which contrasts with the trend as it is expected for apprenticeships and other methods to be least provided.

\section{Distribution of training schemes and programmes within vehicles}

This section examines the vehicles job group in further detail, with the focus being on the areas where there are gaps in the provided training schemes and programmes.

In Figure 23, it can be seen that the majority of courses offered in the vehicles job group are at the operational management level. Specifically, $48 \%$ of the total 63 courses offered are provided at the operational management level; this is similar to the trend in the infrastructure section, however, the distribution is more drastic here. The strategic and tactical management levels each have less than $30 \%$ of the course distribution, meaning that there is less variation as almost half of the courses are offered at one management level.

At both the strategic and tactical management levels, university courses are the most provided, while the operational level has mainly professional training schemes. The next most provided schemes at the operational level are apprenticeship schemes and vocational education and training (VET \& CVET). The strategic and tactical levels each only have 1 apprenticeship scheme, specifically from Australia and Poland.

Figure 24 shows the distribution of courses amongst the fields of education. It follows the same trend as Figure 10, with the majority of the training schemes and programmes in the strategic and tactical management levels being provided by an institution of higher education. Also, the same trend from section 3.2 follows for the operational management level, with the majority of its courses being offered by professional training schemes. 


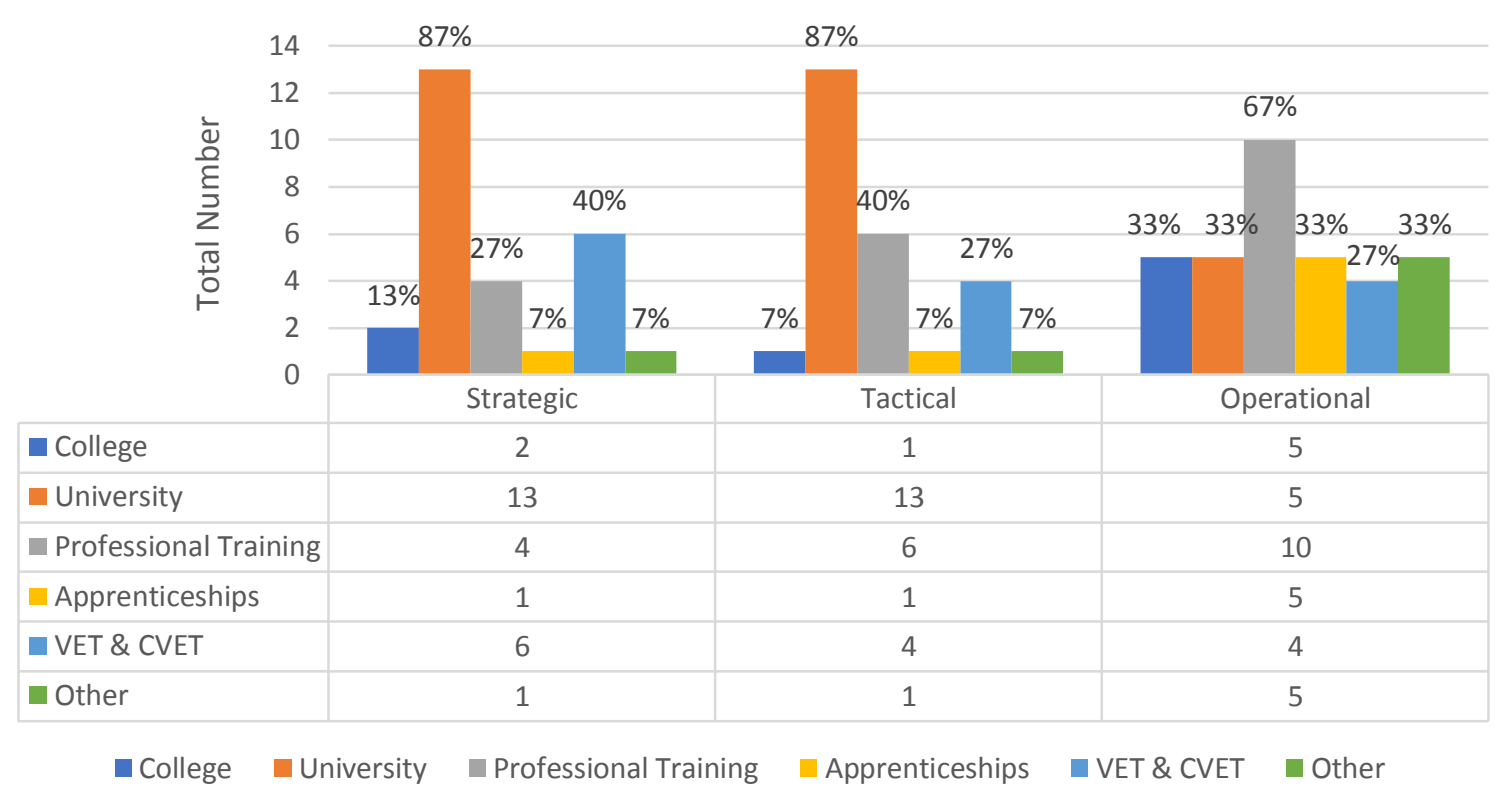

Figure 22. Distribution of training schemes and programmes amongst all fields of education and management levels for the "Infrastructure" job group in all sample countries.

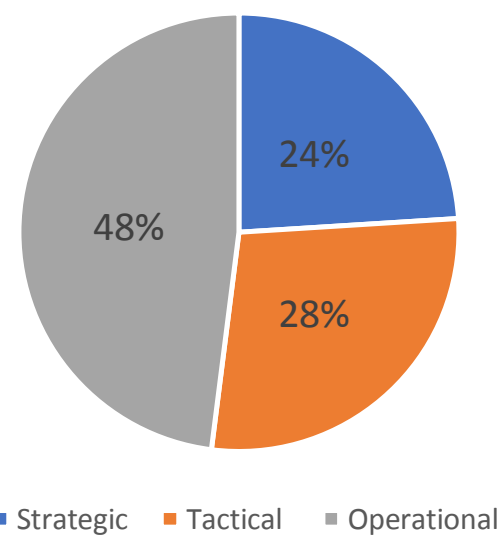

Figure 23. Average distribution of training schemes and programmes spread across the management levels in the "Vehicles" job group.

\section{Distribution of training schemes and programmes within operations}

This section examines the operations job group in further detail, with the focus being on the areas where there are gaps in the provided training schemes and programmes.

Figure 25 shows that the operational management level provides almost $40 \%$ of the 62 courses available in the operations job group. The strategic management level offers just over one-third of the courses within operations, while the tactical management level provides the smallest proportion at $29 \%$.

As seen previously amongst job groups, it can be seen that the most provided training method for the strategic and tactical levels is through university. In contrast, at the operational management level, there is only one university course provided, specifically in Greece. The most provided training method at the operational level is through professional training schemes, whereas there are only 3 of these provided at the tactical management level.

The data shown in Figure 26 follows the general trend seen in the previous sections. Most of the training schemes at the strategic and tactical levels are provided by universities, while the courses at the operational management level are mostly provided by professional training schemes.

\section{Distribution of training schemes and programmes within signalling}

This section examines the signalling job group in further detail, with the focus being on the areas where there are gaps in the provided training schemes and programmes.

Figure 27 shows the distribution of training schemes and programmes in the signalling job group. Nearly $40 \%$ of the 67 courses are provided at the operational management level. Both the strategic and tactical management levels provide around $30 \%$ of the courses in the signalling job group. This shows the distribution is fairly even within the signalling job group.

As seen in the other job groups, university courses are most provided at the strategic and tactical management levels whereas the operational level mainly provides professional training schemes. In contrast, apprenticeships at the operational level are provided by 4 of the 15 sample countries whereas there are none provided at the strategic level and only one provided at 


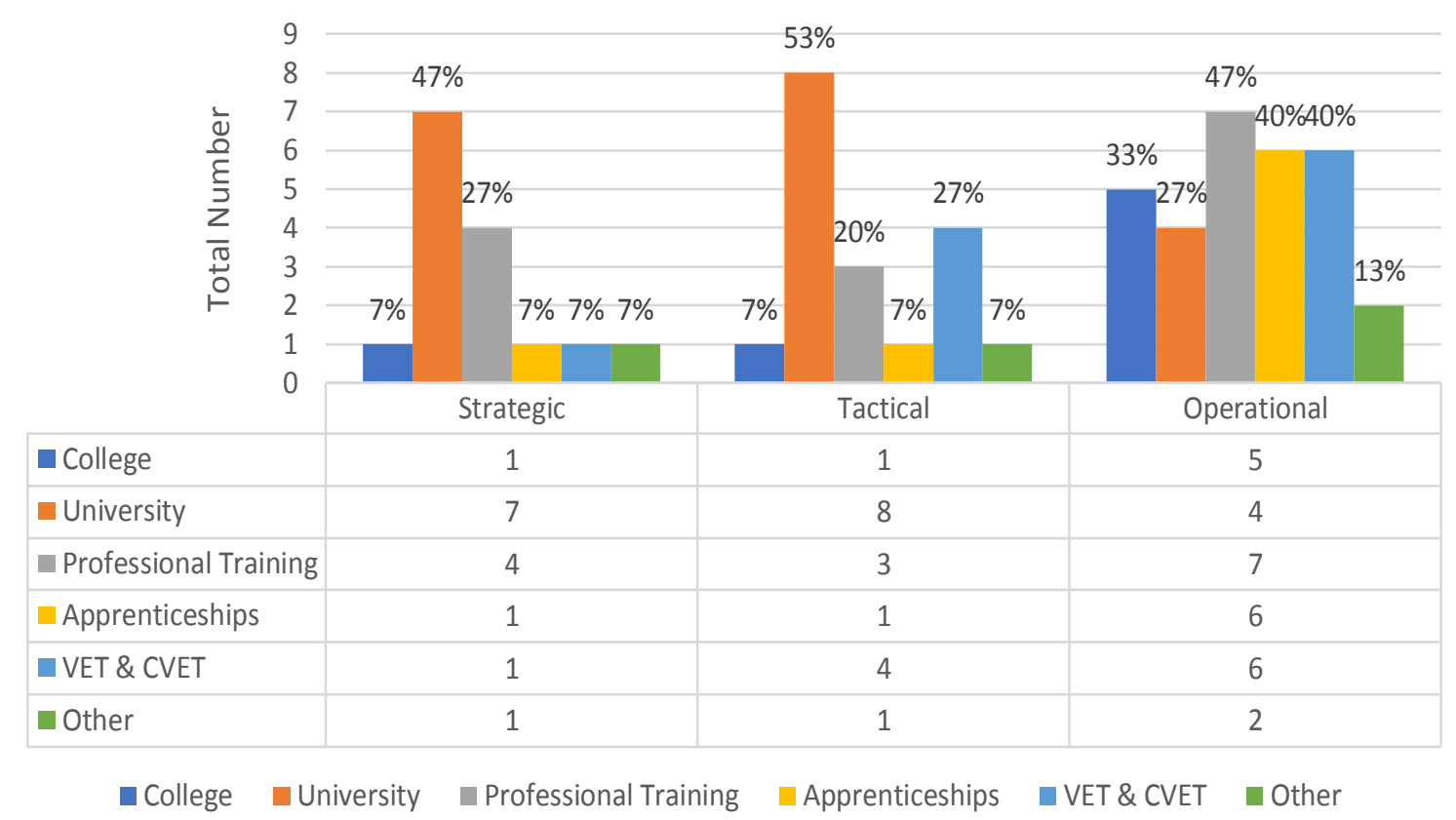

Figure 24. Distribution of training schemes and programmes amongst all fields of education and management levels for the "Vehicles" job group in all sample countries.

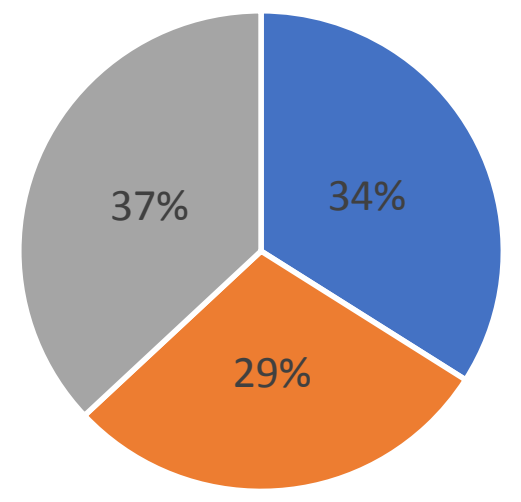

- Strategic $=$ Tactical $=$ Operational

Figure 25. Average distribution of training schemes and programmes spread across the management levels in the "operations" job group.

the tactical level, by Portugal. Furthermore, other training methods are not provided at the tactical level and more are provided at the strategic level than at the operational level, which is unexpected based on Figure 10 in section 3.2.

The data in Figure 28 follows the general trend seen amongst the previous section. The majority of the sample countries provide university courses at the strategic and tactical management levels of training. It should be noted that none of the sample countries offer an apprenticeship scheme at the strategic management level for signalling.
As expected from the trend, the most provided schemes at the operational management level are professional training schemes.

\section{Distribution of training schemes and programmes within economics}

This section examines the economics job group in further detail, with the focus being on the areas where there are gaps in the provided training schemes and programmes.

Figure 29 shows the distribution of training schemes and programmes in the economics job group. The strategic and tactical management levels each provide $35 \%$ of the 54 courses in the economics job group, while the remaining $30 \%$ is provided at the operational management level. This job group is the most evenly distributed as each of the management levels lie close to having one-third of the proportion of training schemes.

The data in Figure 30 follows the general trend for the strategic and tactical management levels however the operational management level diverges from the trend. The majority of the sample countries offer a university course as a form of training at either the strategic or tactical management levels. The operational management level is expected to mainly offer professional training schemes, however, in this job group, vocational education and training (VET \& CVET) is provided most.

It should also be noted that the operational management level is the only one that has apprenticeship schemes in this job group. These are provided by 


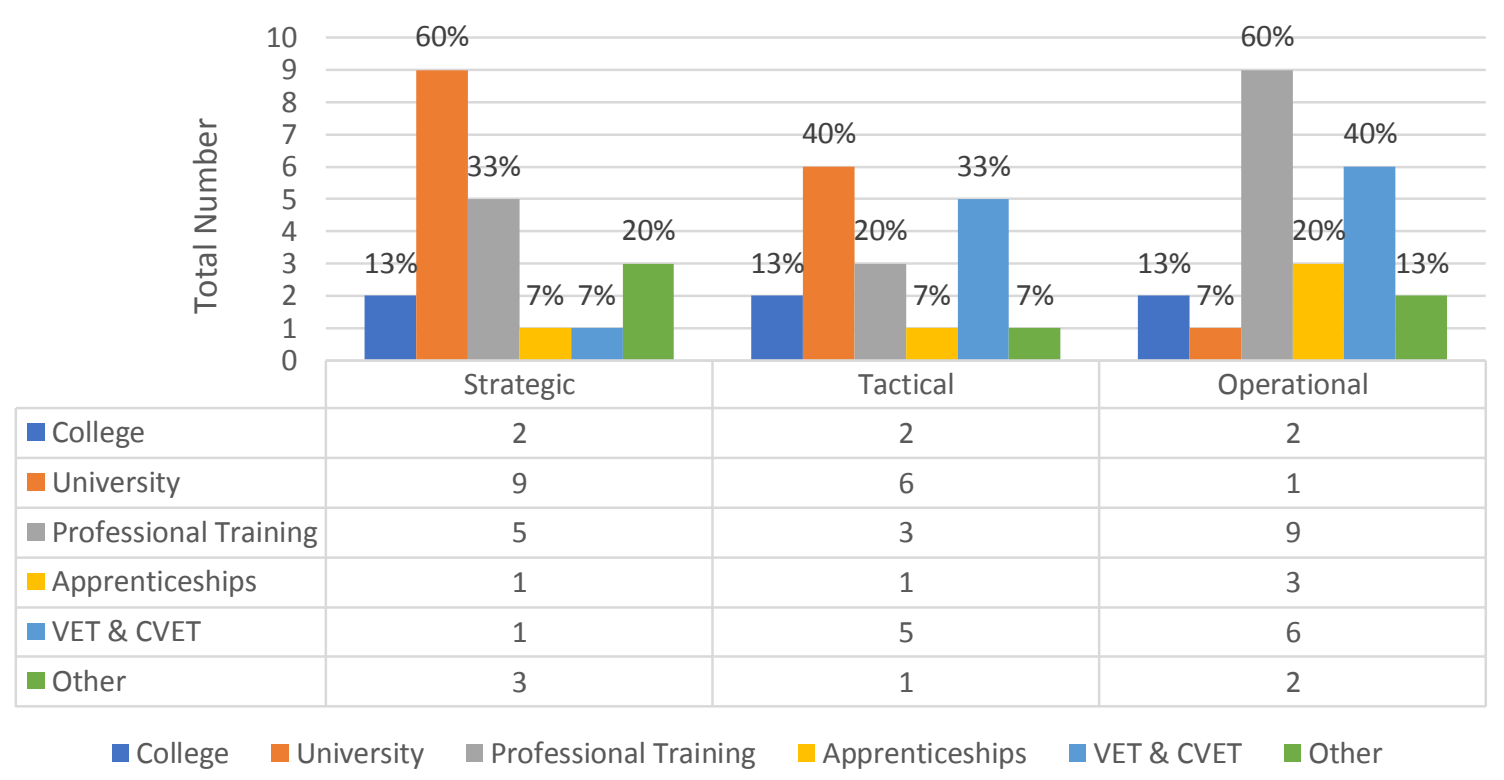

Figure 26. Distribution of training schemes and programmes amongst all fields of education and management levels for the "Operations" job group in all sample countries.

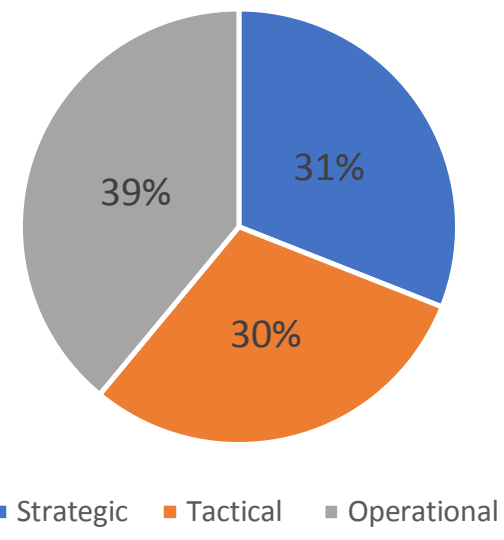

Figure 27. Average distribution of training schemes and programmes spread across the management levels in the "Signalling" job group.

\section{Bulgaria and Greece.}

\section{Distribution of training schemes and programmes within administration}

This section examines the administration job group in further detail, with the focus being on the areas where there are gaps in the provided training schemes and programmes.

Figure 31 shows the distribution of training schemes and programmes in the administration job group. Almost $40 \%$ of the 51 courses are provided at the tactical management level in the administration job group. The strategic and operational management levels both provide about $30 \%$ of the available courses each. It should be noted that this is the only job group in which the tactical management level offers the most courses.

Figure 32 shows the distribution of training schemes and programmes for the administration job group. It should be noted that there is a clear contrast with the general trend seen in the previous sections. The most schemes offered at the tactical management level are by universities, however, the strategic level is provided equally by universities and professional training schemes. The operational level has most of its schemes provided by vocational education and training (VET \& CVET) however it is expected to have more courses provided by professional training schemes.

Apprenticeship schemes and other training methods are not provided at the strategic management level in this job group, while at the other management levels they each have 2 provided. Bulgaria and Greece each provide an apprenticeship scheme at the operational management level; Romania and the United Kingdom each provide an apprenticeship scheme at the tactical management level.

\section{Distribution of training schemes and programmes within academia}

This section examines the academia job group in further detail, with the focus being on the areas where there are gaps in the provided training schemes and programmes.

Figure 33 shows the distribution of training schemes and programmes in the academia job group. $43 \%$ of the 28 courses are provided at the operational level, followed 


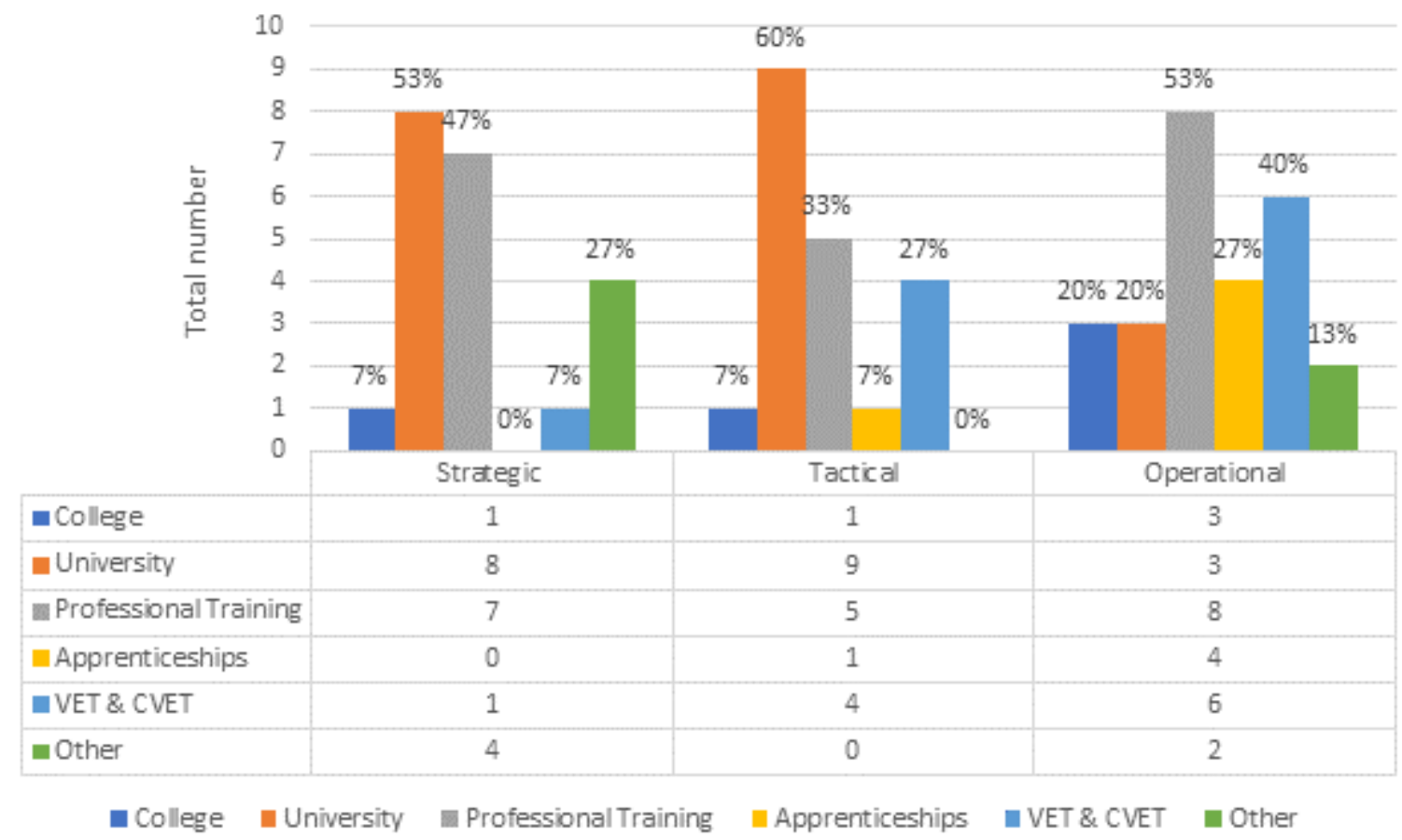

Figure 28. Distribution of training schemes and programmes amongst all fields of education and management levels for the "Signalling" job group in all sample countries.

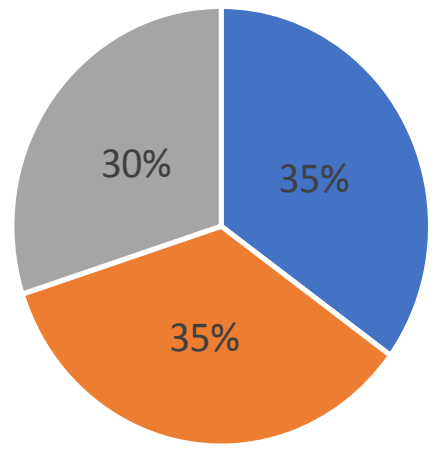

- Strategic - Tactical - Operational

Figure 29. Average distribution of training schemes and programmes spread across the management levels in the "Economics" job group.

by $36 \%$ being provided by the tactical management level. The strategic management level offers the fewest number of courses within the academia job group.

Figure 34 shows the distribution of training schemes and programmes amongst the academia job group. Apprenticeship schemes are unavailable in all of the sample countries in this job group. Each of the management levels are provided most commonly at a university. As jobs within academia are all based around higher education, it would be expected for courses to be available only at institutions of higher education (colleges and universities).

Although the operational management level would be expected to mainly have professional training schemes, only one of these is provided. This scheme is provided by Italy, which also provides the professional training schemes available at the strategic and tactical management levels.

\section{CONCLUSIONS AND FUTURE WORK}

This paper studied the available schemes within the skills development for workers within the rail transport sector. The data gathered showed that there was variety in the number of courses available amongst the 15 sample countries studied. The number of courses available in the sample countries varied from 3 to 54 across each management level. Apprenticeship schemes and other forms of training were found to be least widely available in almost all of the sample countries. Those positions that give workers higher levels of responsibility have more university courses and professional training schemes. To fill these gaps more skills development and training schemes and programmes should be made available in the sample countries.

Non-academic courses are less available within the rail sector, suggesting that businesses should offer more courses as apprenticeship schemes are more social and provide a hands-on learning experience with a lot of 


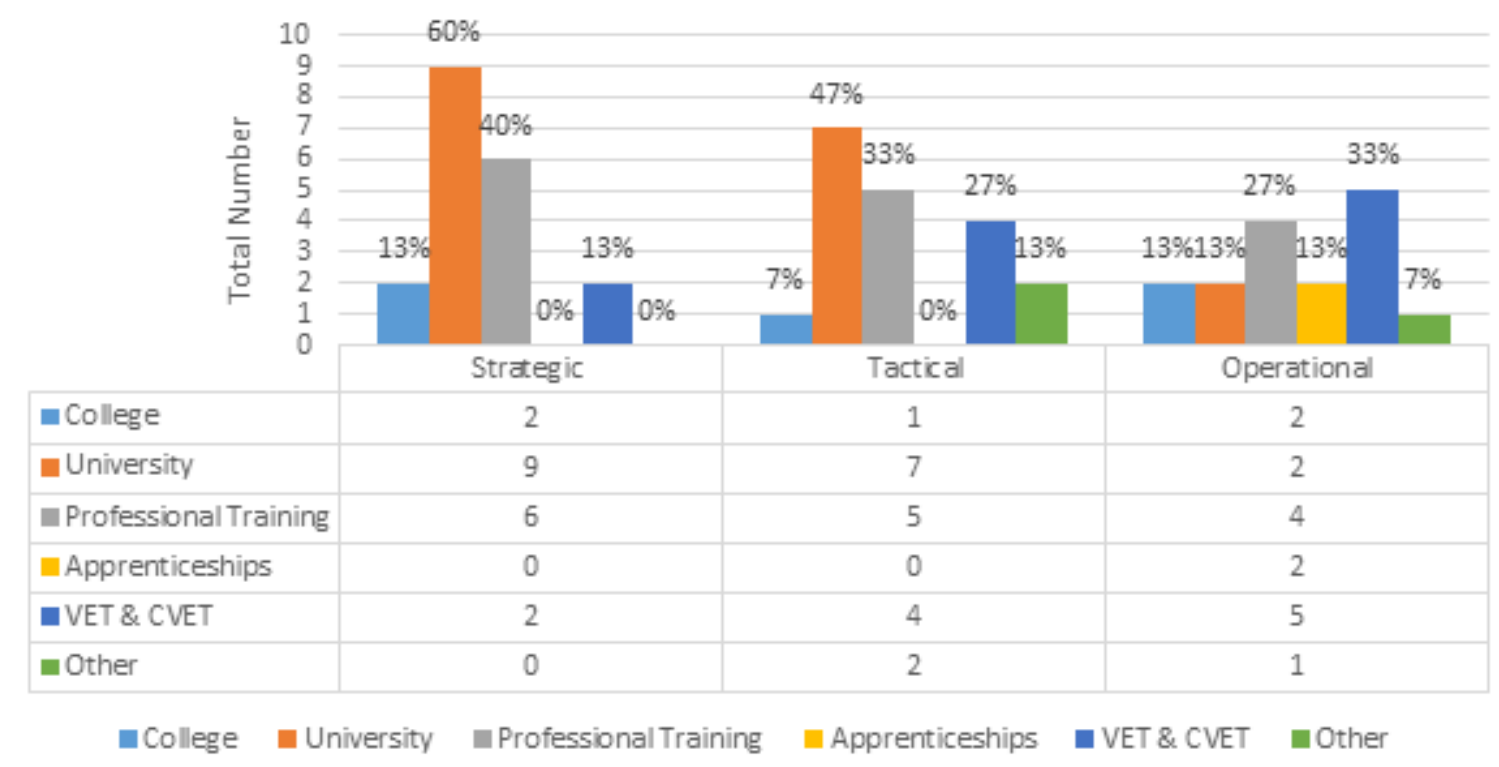

Figure 30. Distribution of training schemes and programmes amongst all fields of education and management levels for the "Economics" job group in all sample countries.

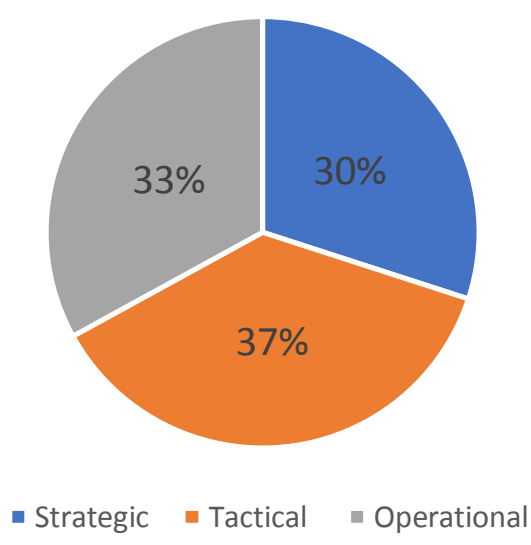

Figure 31. Average distribution of training schemes and programmes spread across the management levels in the "Administration" job group.

support. Being able to undergo an apprenticeship allows the workers to learn and earn, putting them straight into the job, which will be beneficial as the rail workforce is slowly retiring (EC, 2013).

Bulgaria is the country most likely to provide an apprenticeship scheme, followed by Greece and Portugal. The majority of the apprenticeship schemes are provided to workers at the operational management level in the "vehicles" job group.

In contrast, the majority of those working at the operational management level are trained using professional training schemes; $73 \%$ of the sample countries provide professional training for operational level workers within at least 1 job group. This suggests that workers at the operational level are likely to have training whilst working in order to learn with an example.

There is potential for further work in this area to go down several different routes. Increasing the number of sample countries, both within and outside of the EU would help show how the rail systems in countries vary dependent on their economy. Using countries with lower economies would not only remove bias but would also give insight into the condition of their rail systems and allow for further comparisons to be made.

Secondly, research could be done to evaluate the quality and content of the courses available. In order to decide where more skills development is needed, and which courses need improvement, it is important to get a 


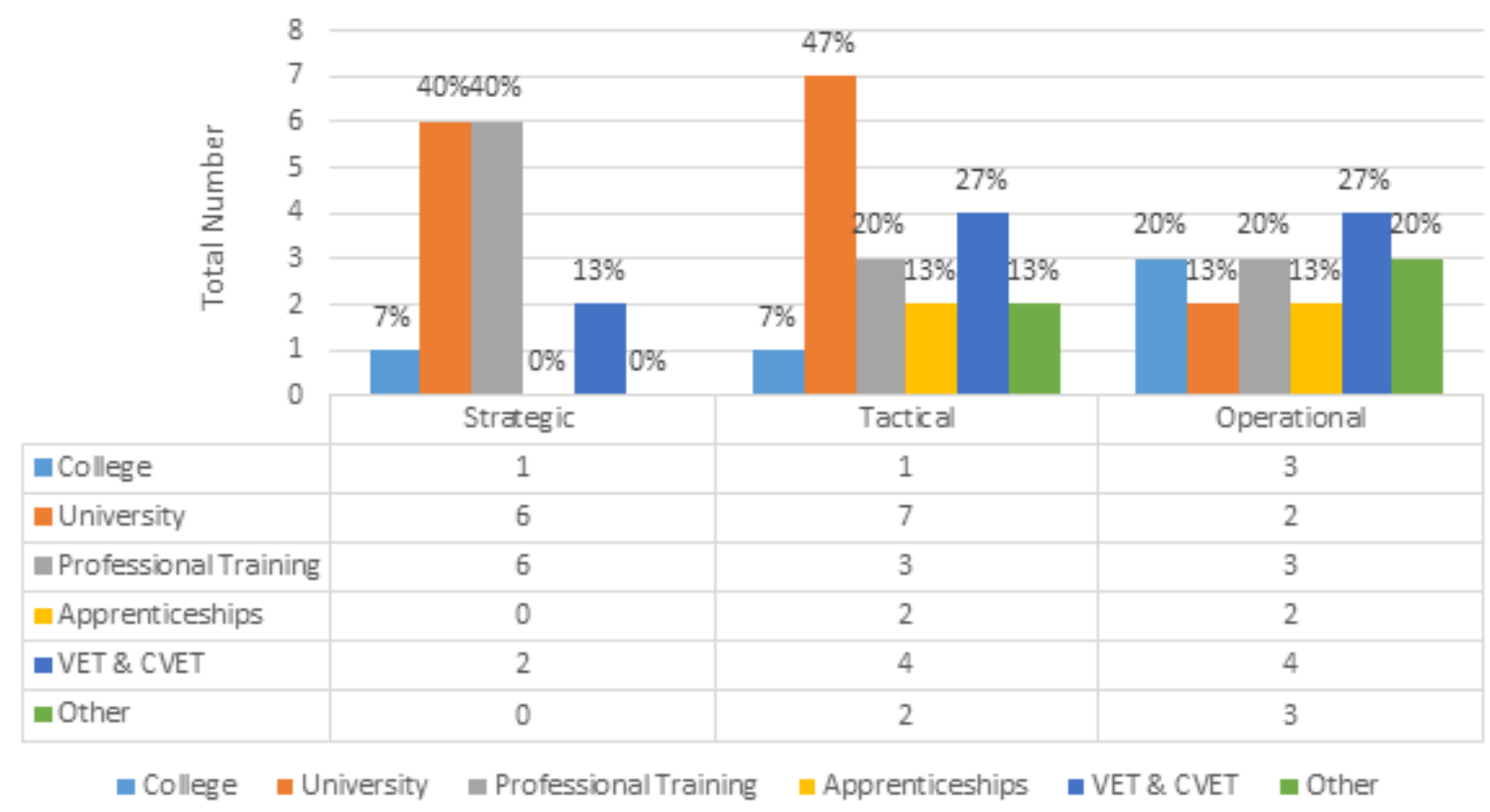

Figure 32. Distribution of training schemes and programmes amongst all fields of education and management levels for the "Administration" job group in all sample countries.

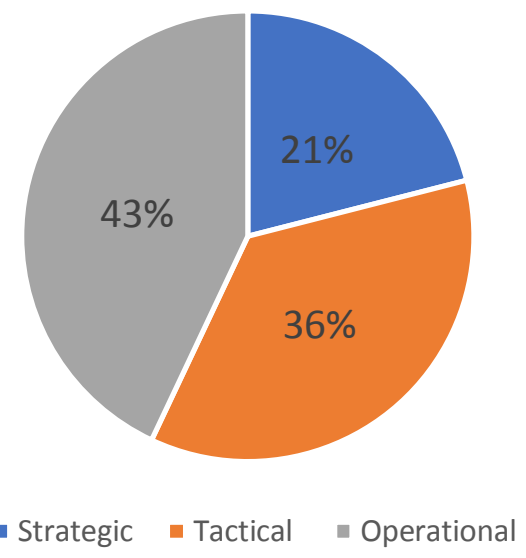

Figure 33. Average distribution of training schemes and programmes spread across the management levels in the "Academia" job group.

further understanding of the courses already provided. More information in this area is required, which could possibly be obtained through course reviews and questionnaires.

In addition, it is important to understand what learning methods are provided already within these courses and whether or not they are effective. It is required to see how they assess those taking the available schemes and programmes. Their assessment methods need to be analysed as to whether they show skill development or not.

Finally, other modes of transport can be compared in the future, comparing the courses amongst each of the 4 transport types; air transport, marine transport, rail transport and road transport.

\section{ACKNOWLEDGEMENTS}

The authors thank the SKILLFUL project for providing the possibility to work on the challenge and the European Commission for providing the funding for the SKILLFUL project. Thanks also go to the partners from the SKILLFUL project helping with data collection and 


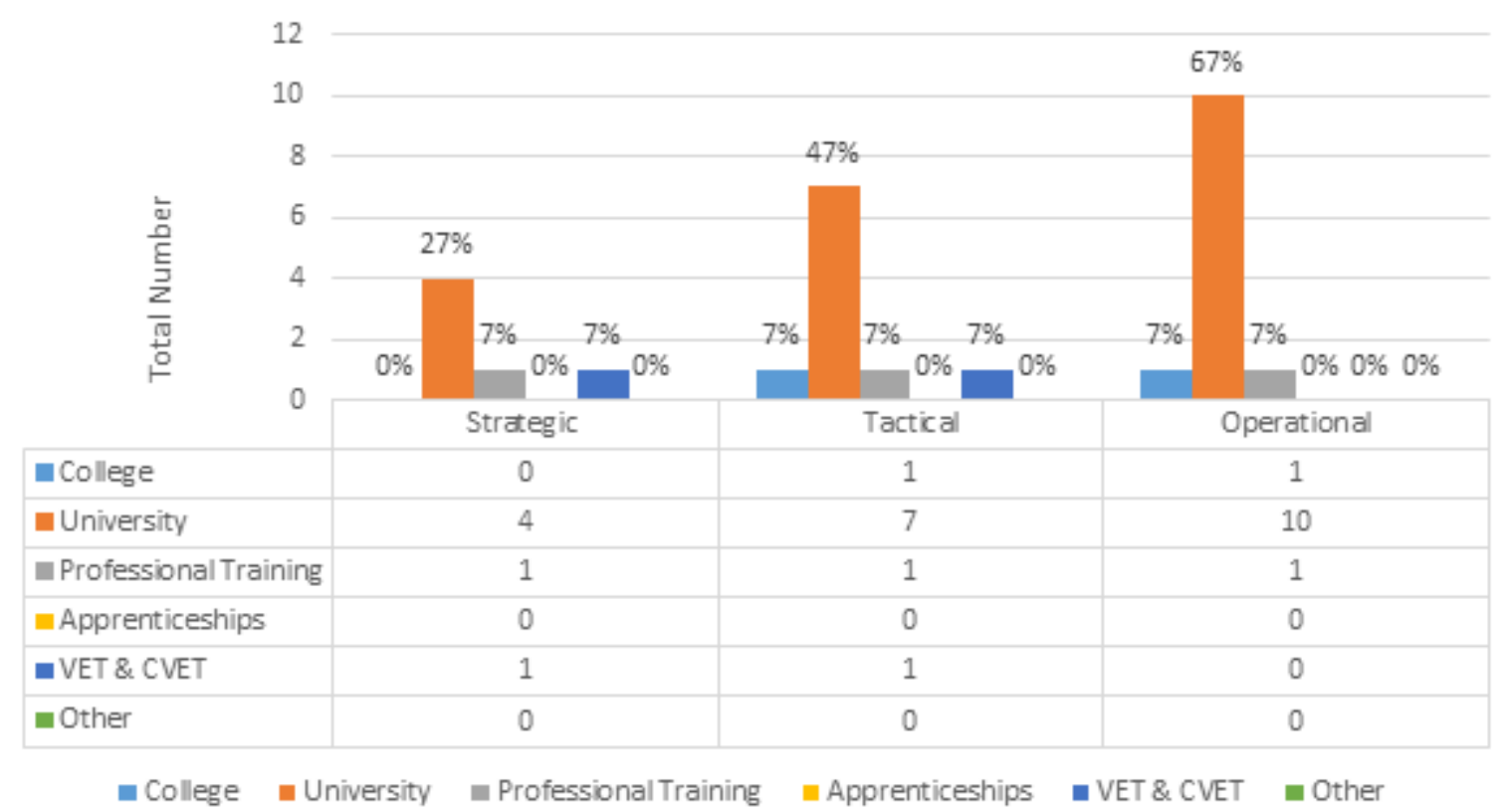

Figure 34. Distribution of training schemes and programmes amongst all fields of education and management levels for the "Academia" job group in all sample countries.

organisation of templates. Special appreciation also goes to the Nuffield Foundation for providing the opportunity to work within NewRail at Newcastle University.

\section{REFERENCES}

Assad A (1980). Models for rail transportation, Transp. Res. Part A, RWA 14A:205-220.

EUROPEAN COMMISSION EC (2013). The Fourth Rail Package, MEMO European Rail: Challenges Ahead, Brussels, 30 January 2013.

Land Transport Authority (2017). SGRA Learning and Programmes (Online). (Last updated June, 2017). Available at: https://www.lta.gov.sg/content/ltaweb/en/academies/singapore-railacademy/sgra-learning-and-programmes.html (Accessed 23 August 2018).

Marinov M, Fraszczyk A (2013a). Curriculum Development and Design for University Programmes in Rail Freight and Logistics, Procedia Soc. Behav. Sci. 141(2014):1166-1170.

Marinov M, Fraszczyk A (2013b). Workshop on Rail Education: academia, industry, research, engagement, promotion, co-operation, Procedia - Soc. Behav. Sci. 00(2013):000-000.

Marinov M, Viegas $\mathbf{J}$ (2011). Tactical management of rail freight transportation services: evaluation of yard performance.
Marinov M, Sahin I, Ricci S, Vasic-Franklin G (2013). Railway operations, time-tabling and control, Research in Transportation Economics 41(1):59-75.

National Academy of Indian Railways (2018). Programmes. (Online). (Last updated August 2018). Available at: http://www.nair.indianrailways.gov.in/view_section.jsp?lang=0\&id=0,2 ,767 (Accessed 23 August 2018).

Network Rail (2017). Industry and Commercial Partners. (Online). (Last updated 2017). Available at: https://www.networkrail.co.uk/industrycommercial-partners/ (Accessed 24 August, 2018).

Newcastle College - Rail Academy (2017). Professional Training Courses. (Online). (Last updated December 2017). Available at: https://www.ncl-coll.ac.uk/railacademy (Accessed 20 August 2018).

Rail Delivery Group (2018). Apprenticeships. (Online). (Last updated 2018). Available at: https://www.raildeliverygroup.com/uk-railindustry/working-in-rail.html (Accessed 24 August 2018).

SKILLFUL (2017). Deliverable D2.1: Best practices on current and emerging training schemes, methodologies and tools in the Transport sector and mapping to future training requirements and scenarios (2017), pp. 13-15.

TunRail (2011). Handbook for Rail Higher Education, Tuning Transatlantic cooperation in rail higher education, 2011, pp. 11-13.

http://sciencewebpublishing.net/jerr 